\title{
Molecular properties of Ankrd26 affected by mutations linked to leukemia and carcinoma formation
}

Sarah A. Hofbrucker-MacKenzie ${ }^{1}$, Klara Metzner $^{1}$, Michael M. Kessels ${ }^{1 *}$, Britta Qualmann ${ }^{1 *}$,

${ }^{1}$ Institute of Biochemistry I, Jena University Hospital - Friedrich Schiller University Jena, 07743

Jena, Germany

* Correspondence

Britta.Qualmann@med.uni-jena.de \& Michael.Kessels@med.uni-jena.de

\section{Short title}

Disease mutants of Ankrd26 


\begin{abstract}
Derailed signaling originating from the plasma membrane is associated with many types of cancer. Mutations in $A N K R D 26$ have been linked to different human cancers and to thrombocytopenia. These mutations include an N-terminal truncation associated with acute myeloid leukemia (AML). We conducted an initial characterization of Ankrd26's protein properties and unveil that an N-terminal amphipathic structure of Ankrd26 lacking in the AML-associated mutant is critical for membrane binding and for Ankrd26's ability to bend membranes by partial membrane insertion. Another Ankrd26 mutation linked to papillary thyroid carcinoma includes truncation and fusion with the kinase domain of the protooncogene RET. Our characterization of Ankrd26 properties reveals that the Ankrd26 part in the Ankrd26-RET fusion mutant is able to anchor the RET kinase domain to the plasma membrane and to mediate self-association - a function we demonstrate to be mediated by Ankrd26's coiled coil domain. Ankrd26-RET fusion led to a massive increase in RET autophosphorylation, i.e. to aberrant RET signaling. Understanding the molecular mechanistic properties of Ankrd26 thus provides important insights into Ankrd26-associated pathomechanisms in human cancer patients.
\end{abstract}

\title{
Keywords
}

acute myeloid leukemia / Ankrd26 disease mutants / ankyrin repeat-containing protein superfamily / membrane binding shaping and curvature sensing / papillary thyroid carcinoma 


\section{Introduction}

The plasma membrane represents the cellular interface to the outer world and thus transmits and integrates a plethora of signals towards the cytoplasm. Plasma membrane-originating signal transduction pathways in turn also modulate the organization and shape of the plasma membrane when cells adapt and respond to such signals. Derailed signaling pathways originating from the plasma membrane are associated with many types of cancer. Thus, proteins linked to signaling pathways that might furthermore spatially organize signaling-competent membrane domains and/or modulate the topology of membranes take center stage in contemporary research.

Several, yet molecularly seemingly very distinct mutations in ANKRD26 have been linked to different human cancers (Cerami et al, 2012; Marconi et al, 2017; Staubitz et al, 2019) and also to thrombocytopenia (Noris et al, 2011; Pippucci et al, 2011; Bluteau et al, 2014). These mutations include a deletion of a more $\mathrm{C}$ terminal part of Ankrd26 leading to a disruption of Ankrd26's binding to PIDD1 - a component of a multi-protein complex (PIDDosome) involved in the cellular response to extra centrosomes (Cerami et al, 2012; Fava et al, 2017; Evans et al, 2021; Burigotto et al, 2021). More recently, an N-terminal truncation has been found to be associated with acute myeloid leukemia (AML) (Marconi et al, 2017). Furthermore, the cancer-linked Ankrd26 mutations include a C terminal Ankrd26 truncation and fusion with a part of the protein product of the protooncogene RET (rearranged during transfection) (Staubitz et al, 2019) - the tyrosine kinase signaling component of multisubunit receptor complexes for glia cell line-derived neurotrophic factor (GDNF) family ligands (GFLs), which frequently shows partial recombination with other genes in a variety of cancers (Shaw et al, 2013; Liu et al, 2021).

The cancer-associated Ankrd26 mutations found up to today are molecularly heterogeneous and therefore do not provide an easy avenue to understanding Ankrd26-associated diseases. Similarly, although Ankrd26 was first described as protein with similarities to POTEs (expressed in prostate, 
ovary, testis, and placenta) (Bera et al, 2002; Bera et al, 2008), which based on their association with poor prognosis in ovarian and other cancers, are considered as potential biomarkers and therapeutic targets (Bera et al, 2006; Redfield et al, 2013), the comparison of Ankrd26 to POTE proteins is unrewarding. First, also functions and molecular properties of POTEs are largely unknown. Second, the suggested similarity of POTEs to Ankrd26 is in fact very limited. Although both contain ankyrin repeats, they reside in the middle in POTEs (Bera et al, 2002) but in the $\mathrm{N}$ terminal part in Ankrd26. Also, Ankrd26 lacks the cysteine-rich domain typical for POTEs (Bera et al, 2002). Due to this lack of knowledge about the properties and molecular characteristics of Ankrd26, Ankrd26 dysfunctions in pathophysiological processes in human patients largely remained elusive.

We unveil that Ankrd26 is a plasma membrane-binding protein that has the ability to shape membranes by employing an $\mathrm{N}$ terminal, membrane-inserted amphipathic structure and a membrane curvature-sensing ankyrin repeat array. Furthermore, Ankrd26 is able to form larger arrays by selfassociation. The discovered properties of Ankrd26 and the underlying molecular mechanisms we were able to dissect clearly experimentally demonstrate that Ankrd26 is a member of the recently suggested N-Ank protein superfamily (Wolf et al, 2019). The AML-associated mutation of Ankrd26 disrupted the membrane binding and shaping capability of Ankrd26. The cancer-associated RET fusion led to a protein that is fully self-association-competent, is constitutively targeted to the plasma membrane and results in aberrant RET signaling by a massive increase in RET autophosphorylation. Understanding the molecular mechanistic properties of Ankrd26 significantly advances our understanding of Ankrd26-associated pathomechanisms in human cancer patients. 


\section{Results}

\section{Ankrd26 associates with the plasma membrane using an $\mathrm{N}$-Ank module}

Ankrd26 is involved in several types of cancer (Cerami et al, 2012; Marconi et al, 2017; Staubitz et al, 2019). Yet, the molecular properties and the functions of Ankrd26 largely remained elusive. Ankrd26associated thrombocytopenia is caused by 5'UTR mutations that seem to lead to some $\mathrm{N}$ terminal truncation. Also an AML-associated mutation of Ankrd26 is marked by an N-terminal truncation of Ankrd26 (Marconi et al, 2017). These findings urgently call for thus far lacking in-depth-analyses of Ankrd26's $\mathrm{N}$ terminal part because understanding its molecular properties and functions provides direct insights into the respective Ankrd26-mediated pathomechanisms.

Although Ankrd26 has been described as cytosolic protein in neurons and glia cells (Acs et al, 2015), subcellular fractionation studies unveiled that the vast majority of was not detected in cytosolic fractions. Instead, Ankrd26 showed a strong membrane association. Similar to farnesylated mCherry (CherryF) coexpressed as marker for constitutively plasma membrane-associated proteins, a significant portion of Ankrd26 was detected in the fractions P2 and P2' (Fig 1A,B).

Also in intact cells, Ankrd26-GFP specifically localized to folds of the plasma membrane marked by CherryF (Fig 1C,D; Fig EV1A,B). These fluorescent microscopical analyses thus were in line with the results of the fractionation studies.

Sequence analyses and structure predictions of human Ankrd26 unveiled five $\mathrm{N}$ terminal ankyrin repeats between amino acid 47 and 207 and an $\mathrm{N}$ terminal amphipathic structure, which together may represent an N-Ank module (Fig 1E,F; Fig EV1C,D). Indeed, purified, recombinant human Ankrd26 $6^{1-217}$ (hu Ankrd26 $6^{\mathrm{N}-A n k}$ ) coprecipitated with liposomes in in vitro reconstitutions (Fig 1G). In contrast, an $\mathrm{N}$ terminal deletion mutant of Ankrd26 lacking the suggested amphipathic structure (hu Ankrd26 ${ }^{\text {Ank }}$, hu Ankrd ${ }^{45-217}$ ) was severely impaired in liposome binding (Fig 1H,I). The $\mathrm{N}$ terminus of Ankrd26 thus is critical for Ankrd26's membrane association. 
Similar results were obtained for the mouse Ankrd26 N-Ank module (ms Ankrd26 ${ }^{\mathrm{N}-\mathrm{Ank}}$, ms Ankrd26 ${ }^{1-}$ ${ }^{208}$ ) and the respective deletion mutant (ms Ankrd26 ${ }^{\text {Ank }}$, ms Ankrd26 $6^{11-208}$ ), respectively. Deletion of the $\mathrm{N}$ terminus suppressed the membrane binding of mouse Ankrd26 almost completely (Fig 1J-M). Also in cells, both mouse and human Ankrd26 N-Ank modules clearly colocalized with CherryF at the plasma membrane, whereas both corresponding $\mathrm{N}$ terminal deletion mutants failed to show any specific membrane localization (Fig 1N,O; Fig EV2).

Ankrd26 thus is a membrane binding protein, associates with membranes directly, as proven by in vitro reconstitution using purified components, and uses an $\mathrm{N}$ terminal domain that may resemble an $\mathrm{N}-$ Ank module for this function both in vitro and in vivo.

\section{A mutated Ankrd26 N-Ank domain found in AML patients is deficient for membrane binding}

The N-Ank module-mediated membrane binding of Ankrd26 suggested that an ANKRD26 mutation found in AML patients, which gives rise to an $\mathrm{N}$ terminal deletion (Marconi et al, 2017), represents a loss-of-function mutation for Ankrd26's N-Ank-mediated membrane binding (Fig 2A). Indeed, the disease mutation identified in AML in the context of the N-Ank module (hu Ankrd26 ${ }^{*}$ AML; Ankrd26 $6^{78-217}$ ) completely failed to associate with membranes in in vitro reconstitutions (Fig 2B-D).

Fractionation experiments showed that hu Ankrd26 ${ }^{*}{ }^{\mathrm{AML}}$ failed to show association with the membrane fractions P2 and P2', whereas the corresponding WT protein (Ankrd26 ${ }^{\mathrm{N}-\mathrm{Ank}}$ ) was detectable in both P2 and P2' (Fig 2E,F). Consistently, hu Ankrd26* AML also failed to properly localize to the plasma membrane. Instead, hu Ankrd26* AML was distributed aberrantly in the cytosol (Fig 2G).

Thus, the involvement of Ankrd26 in AML seems to be related to a defective membrane targeting of the Ankrd26 mutant found in AML patients. 


\section{The amphipathic N terminus lacking in the Ankrd26 AML mutant is important for Ankrd26's} tight membrane binding

We next addressed the mechanisms of Ankrd26's membrane association disrupted by the $\mathrm{N}$ terminal deletion in the Ankrd26 AML mutant. An N terminal amphipathic structure may mediate integration into the membrane instead of mere electrostatic surface association. Indeed, the WT Ankrd26 N-Ank module was not sensitive to suppressing electrostatic interactions by rising salt concentrations but showed full salt resistance even at $250 \mathrm{mM} \mathrm{NaCl}$ (Fig 3A,B). Similarly, also the membrane-binding of mouse Ankrd26 $6^{\mathrm{N}-\mathrm{Ank}}$ was resistant to suppression of electrostatic interactions (Fig EV3A,B). In contrast, the (reduced) membrane binding of Ankrd26 ${ }^{\text {Ank }}$ (compare also Fig 1H,I) was sensitive to rising salt concentrations and therefore apparently predominantly based on electrostatic interactions (Fig 3C,D).

The amphipathic nature of the $\mathrm{N}$ terminal key element for Ankrd26's tight membrane association was then proven by two sets of mutations erasing on one side two fully conserved hydrophobic residues (I4E, F5E) and on the other side seven hydrophilic, positively charged residues (Fig 3E). Both mutants showed significantly reduced membrane binding in quantitative studies (Fig 3F-K).

Importantly, mutation of the two hydrophobic residues isoleucine 4 and phenylalanine 5 was sufficient to render Ankrd26 susceptible to electrostatic suppression of membrane association. It can therefore be concluded that the ability of Ankrd26 $6^{\mathrm{N}-\mathrm{Ank}}$ to tightly bind to membranes relies on hydrophobic membrane associations and embedding into the hydrophobic phase of the membrane (Fig 3L,M).

Ankrd26's ankyrin repeat array is able to sense membrane curvature and prefers to associate with strongly convex curvatures 
3D-modeling of Ankrd26's ankyrin repeat array suggested a curved and rotationally twisted structure brought about by tight lateral stacking of the individual ankyrin repeats (Fig $\mathbf{3 N}$ ). This suggested that Ankrd26's ankyrin repeat array may prefer membrane surfaces, which offer better fitting curvatures, while the full N-Ank module with its ability to intercalate an amphipathic structure into one leaflet of the membrane may have the power to actively shape membranes into bent topologies, which may then also fit the curved ankyrin repeats. According to this hypothesis, the ankyrin repeats of Ankrd26 may thus be able to discriminate different curvatures of membranes. Offering small unilamellar vesicles (SUVs; average size $~ 50 \mathrm{~nm}$; compare Wolf et al, 2019) versus large ones (LUVs) indeed led to an enhanced membrane binding of Ankrd26 ${ }^{\text {Ank }}$ (Fig 3O,P). Similarly, the mouse Ankrd26 ankyrin repeat array with its very weak membrane binding also was able to sense the curvature of membranes and strongly preferred SUVs (170\% above LUV binding; $P<0.01$; Fig EV3C,D).

Importantly, the very weak membrane binding of the disease mutant Ankrd26 ${ }^{\mathrm{N}-\mathrm{Ank}}{ }^{\mathrm{AML}}$ also was significantly enhanced upon offering strongly curved membrane surfaces represented by SUVs instead of the only very moderately curved LUVs (Fig 3Q,R).

The Ankrd26 ankyrin repeat array thus senses membrane curvature and prefers more strongly convexly curved membrane surfaces.

\section{Ankrd26 is a membrane shaping protein and this function relies on the amphipathic $\mathbf{N}$ terminus}

Freeze-fracturing of liposomes allows for a reliable visualization of liposomes with sizes over several orders of magnitude by transmission electron microscopy (TEM) (Fig 3S-V). Control incubations with buffer alone or with an unrelated protein (GST) mostly showed larger liposomes (Fig 3S,T). In contrast, liposomes incubated with Ankrd2 $6^{\mathrm{N}-\mathrm{Ank}}$ were marked by an ample presence of small liposomes (Fig 3U). 
In line with the critical importance of the amphipathic $\mathrm{N}$ terminus for membrane binding and intercalation, incubation with Ankrd26 ${ }^{\text {Ank }}$ lacking the amphipathic $\mathrm{N}$ terminus merely led to liposomes resembling the large liposomes observed in the control incubations (Fig 3V).

Quantitative determinations clearly demonstrated that Ankrd26 $6^{\mathrm{N}-\mathrm{Ank}}$ had a strong and highly statistically significant effect on membrane topology. Ankrd $26^{\mathrm{N}-\text { Ank }}$-incubated liposomes with in average $\sim 300 \mathrm{~nm}$ diameter showed only about half the size of controls or incubations with the deletion mutant Ankrd26 ${ }^{\text {Ank }}$ (mean, $\sim 600 \mathrm{~nm}$ ) (Fig 3W). Thus, the complete N-Ank module has the power to actively convert membrane topologies into more strongly curved ones and the amphipathic $\mathrm{N}$ terminus is absolutely crucial for the membrane shaping ability of Ankrd26.

Distribution analyses of liposome diameters observed in incubations with unrelated protein, Ankrd26 $6^{\mathrm{N}-\mathrm{Ank}}$ and Ankrd26 ${ }^{\text {Ank }}$, respectively, clearly showed that especially liposomes with small diameters were much more abundant in incubations with Ankrd26 $6^{\mathrm{N}-A n k}$ than in controls. Especially in the size categories of $100 \mathrm{~nm}$ and beneath, their frequencies were 2-5fold as high as those of liposomes incubated with Ankrd26 ${ }^{\text {Ank }}$ or as those of the control incubations (Fig 3X).

SUVs generated by sonication of LUVs roughly have diameters around $50 \mathrm{~nm}$ (Wolf et al, 2019). The curvatures of the more abundant small liposomes observed in EM analyses of liposomes incubated with Ankrd26 $6^{\mathrm{N}-\mathrm{Ank}}$ thus were in the same order of magnitude as those of the SUVs that were preferred by the Ankrd26 ankyrin repeat array in the SUV versus LUV binding studies (Fig 30,P).

\section{The papillary thyroid carcinoma-associated fusion of parts of Ankrd26 and RET exhibits a}

\section{membrane localization mediated by the Ankrd26 portion}

The mutated Ankrd26 found in AML patients showed an impaired membrane binding. Alterations in plasma membrane association may also play a role in the pathophysiology of the Ankrd26-RET fusion found in papillary thyroid carcinoma, as RET is normally anchored in the membrane by a 
transmembrane domain and RET kinase signaling thus originates from the plasma membrane. The entire $\mathrm{N}$ terminal half of RET including the transmembrane domain, however, was lacking in the piece of RET (aa712-1114) included in the Ankrd26-RET fusion found in papillary thyroid carcinoma. Instead, only the C terminal tyrosine kinase domain of RET was present in the Ankrd26RET fusion and was fused to Ankrd26 $6^{1-1405}$ (Straubitz et al, 2019). We therefore first addressed the membrane binding of RET and $\operatorname{RET}^{712-1114}$ (Fig 4A-D). Wild-type RET-GFP was found along the secretory pathway (ER, Golgi) - as expected for a transmembrane protein - and showed a good spatial overlap with CherryF at the plasma membrane (Fig 4A). Cofractionation with CherryF (Fig 4B) clearly confirmed the plasma membrane association of RET-GFP. In contrast, RET ${ }^{712-1114}$-GFP did neither localize with CherryF at the plasma membrane nor cofractionated with this plasma membrane marker (Fig 4C,D).

RET signaling normally originates from the plasma membrane. Interestingly, fusion of Ankrd26 ${ }^{1-1405}$ with RET $^{712-1114}$ restored a plasma membrane-targeting of the RET kinase domain, as the Ankrd fragment Ankrd26 $6^{1-1405}$ turned out to be fully membrane binding-competent and by fusion conferred this ability to $\mathrm{RET}^{712-1114}$, as evidenced by colocalization and cofractionation of the papillary thyroid carcinoma-associated Ankrd26-RET fusion with CherryF in different cells (Fig 4E-H).

Thus, in papillary thyroid carcinoma expressing Ankrd26-RET, aberrant signaling pathways seem not to originate from the fact that Ankrd26 was not correctly anchored at the plasma membrane or that RET was not localized to the plasma membrane. Rather, it seemed that some other mechanisms are involved in the aberrant signaling of the Ankrd26-RET fusion leading to papillary thyroid cancer.

\section{Self-association of RET is restored by a related property of Ankrd26 in the Ankrd26-RET fusion found in papillary thyroid carcinoma}


The fusion of the protooncogene RET with $A N K R D 26$ found in papillary thyroid carcinoma patients only comprises the sequence encoding for the RET amino acids 712 to 1114 (Staubitz et al, 2019), which - quite common in RET fusions identified in cancer (Shaw et al, 2013; Liu et al, 2021) encodes for the kinase domain of RET (Takahashi and Cooper, 1987) (Fig 5A,B). The lacking N terminal half of RET encodes for its extracellular part and the transmembrane domain. Membrane association is normally ensured by the transmembrane domain of RET but this aspect of RET signaling was restored by fusing the C terminal RET fragment to Ankrd26 ${ }^{1-1405}$ (Fig 4), which comprises a fragment of the predicted extended coiled coil domain of Ankrd26 and the membranebinding N-Ank module (Fig 5C,D). However, another aspect important for RET signaling is the assembly of RET in multireceptor complexes (Mulligan, 2014). Crosslink studies with RET-GFP and the zero-length crosslinker EDC were able to demonstrate this RET property in HEK293 cells (Fig 5E). EDC crosslink led to a high molecular weight band at above $460 \mathrm{kD}$ reflecting RET selfassociation products. These RET self-association products increased with rising crosslinker concentrations and were to some extent even visible without crosslinker suggesting that they are in part even SDS-resistant (Fig 5E).

In contrast, the RET fragment $\left(\mathrm{RET}^{712-1114}\right)$, which is fused to Ankrd26 in the papillary thyroid carcinoma-linked Ankrd26-RET fusion, was unable to self-associate. Only the monomeric band of $\mathrm{RET}^{712-1114}$-GFP $(53 \mathrm{kD})$ was seen irrespective of the concentration of crosslinker used (Fig 5F). The RET fragment comprised in the papillary thyroid carcinoma Ankrd-RET fusion thus lacks the RET self-association ability critical for RET signaling.

Interestingly, related experiments with Ankrd26-GFP clearly demonstrated that similar to RET also Ankrd26 gave rise to high molecular weight self-association products when incubations with EDC were subjected to immunoblotting analyses (Fig 5G). Corresponding to the increasing high molecular weight self-association products, the band reflecting monomeric full-length Ankrd26-GFP (about 240 
$\mathrm{kD})$ and also the bands reflecting GFP-containing proteolytic fragments of Ankrd26 declined with rising EDC concentrations (Fig 5G).

The use of deletion mutants demonstrated that the self-association capability of Ankrd26 we observed was not mediated by Ankrd26's N-Ank module (Fig 5H). Instead, it clearly was a property of the C terminal coiled coil domain of Ankrd26 (Fig 5I). Instead of dimers, it mostly were higher order assemblies with apparent molecular weights above $500 \mathrm{kD}$ that were formed (Fig 5I).

The fusion at the position of aa1405 of Ankrd26 with RET found in papillary thyroid carcinoma represents a disruption of Ankrd26's coiled coil domain, which spans the region between aa500 and aa1600 (Fig 5C,D). Interestingly, both Ankrd26 $6^{1-1405}$ as well as Ankrd26 $6^{490-1405}$ still were able to efficiently self-associate despite the deletion of all coiled coil domain residues beyond the RET fusion point (Fig 5J,K). This suggested that, despite the partial disruption of Ankrd26's coiled coil domain, the remaining part of Ankrd26 still is able to self-associate and could therefore also confer such functions to the papillary thyroid carcinoma-linked Ankrd26/RET fusion. Studies with Ankrd26 ${ }^{1-1405}$ $\mathrm{RET}^{712-1114}$ indeed showed that the fusion product was able to self-associate. Self-association products at a size of about $500 \mathrm{kD}$ were clearly detectable and rose with rising EDC concentration, while low molecular weight bands of the Ankrd26 $6^{1-1405}-$ RET $^{712-1114}$ fusion declined correspondingly (Fig 5L).

\section{The Ankrd26 ${ }^{1-1405}-$ RET $^{712-1114}$ fusion found in papillary thyroid carcinoma shows increased RET autophosporylation}

Our studies so far demonstrated that both key aspects of RET signaling, the self-association and the membrane localization of RET are disrupted in $\mathrm{RET}^{712-1114}$ but fully restored by fusion to Ankrd26 ${ }^{1-}$ 1405. The Ankrd26 ${ }^{1-1405}-\mathrm{RET}^{712-1114}$ fusion found in papillary thyroid carcinoma patients thus did not seem to reflect dominant-negative RET functions. Rather fusion with Ankrd26 $6^{1-1405}$ could theoretically generate a constitutively active form of RET that due to the deletion of the $\mathrm{N}$ terminus of RET would 
be decoupled from ligand binding. GFL-binding of one of the four GDNF receptor- $\alpha$ (GFR $\alpha$ ) family members serving as coreceptors leads to RET recruitment, RET dimerization and subsequent RET autophosphorylation at multiple tyrosines including e.g. Y753, Y905, Y981, Y1015 and Y1062. RET autophosphorylation then leads to a recruitment of a variety of signaling components responsive to phosphorylated tyrosines and to the assembly of larger signaling complexes (Mulligan, 2014). RET phosphorylations thereby reliably reflects the activity of RET signaling. The commercial availability of specific anti-RET pY905 antibodies suitable for fluorescence detection of anti-RET pY905 (pRET) together with general anti-RET and anti-GFP immunodetection allowed us to directly address and compare the levels of autophosphorylation of RET, of the $\mathrm{RET}^{712-1114}$ fragment and of the Ankrd $26^{1-}$ ${ }^{1405}-\mathrm{RET}^{712-1114}$ fusion found in papillary thyroid cancer and to thereby compare the RET kinase signaling activities elicited by these three proteins. Importantly, lysates obtained from cells transfected with the papillary thyroid carcinoma fusion mutant Ankrd26 $6^{1-1405}-\mathrm{RET}^{712-1114}$ demonstrated that, despite the low expression of the mutant consistently shown by both anti-GFP and anti-RET antibodies, fusing the membrane targeting- and self-association-competent Ankrd26 part with the kinase domain of RET led to strong RET signaling, as determined by Y905 phosphorylation (Fig 6AC).

Quantitative determinations of the pY905 phosphorylation in $\mathrm{RET}^{712-1114}$, in RET and in Ankrd26 ${ }^{1-}$ ${ }^{1405}-\mathrm{RET}^{712-1114}$ in relation to the anti-GFP-detected protein expression levels showed that RET kinase activity levels of Ankrd26 $6^{1-1405}-\mathrm{RET}^{712-1114}$ were about $500-700 \%$ of that of RET or the RET kinase domain alone (Fig 6D). Similar differences were obtained when pRET data were expressed as pRET/RET signals. Whereas RET and $\mathrm{RET}^{712-1114}$ did not show any differences, again, the Ankrd26 ${ }^{1-}$ ${ }^{1405}-\mathrm{RET}^{712-1114}$ fusion mutant showed autophosphorylation levels that were more than 5-20times higher than those of RET or the RET kinase domain (Fig 6E). 
bioRxiv preprint doi: https://doi.org/10.1101/2021.05.19.444897; this version posted May 20, 2021. The copyright holder for this preprint (which

was not certified by peer review) is the author/funder, who has granted bioRxiv a license to display the preprint in perpetuity. It is made available under aCC-BY-NC-ND 4.0 International license.

Fusion of the membrane-binding and self-association-competent part of Ankrd26 with the kinase domain of RET, as found in papillary thyroid carcinoma patients (Staubitz et al, 2019), thus leads to a fusion protein with a massively increased autophosphorylation of RET. 


\section{Discussion}

Derailed signaling pathways associated with many types of cancer often originate from the plasma membrane. The development of causal therapies relies on knowledge of the involved pathomechanisms of the different types of cancer. During the last years, a variety of ANKRD26 mutations have been described as linked to different malignancies (Cerami et al, 2012; Marconi et al, 2017; Staubitz et al, 2019). In line with some crucial importance of the $\mathrm{N}$ terminus of Ankrd26 for proper function, monoallelic single nucleotide substitutions in the 5'UTR of the ANKRD26 gene leading to the use of another start codon further 3' and thereby to $\mathrm{N}$ terminal truncation of Ankrd26 are linked to thrombocytopenia - an autosomal dominant bleeding disorder - and AML (Pippucci et al, 2011; Noris et al, 2013; Bluteau et al, 2014; Marconi et al, 2017). Fusion of a C terminally truncated Ankrd26 with RET also leads to cancer (Straubitz et al, 2019). Yet, little was known about the properties of the Ankrd26 protein as such. Our analyses unveil several molecular Ankrd26 functions affected by the disease mutations and thereby shed light on Ankrd26-related pathomechanisms.

We show that Ankrd26 is a plasma membrane-binding protein, whose ankyrin repeats are part of a functional N-Ank module for membrane binding as well as for membrane curvature induction and sensing. The N-Ank module-mediated functions of Ankrd26 seem to be of critical physiological relevance, as exactly membrane binding and membrane curvature induction were disrupted in the analyzed AML-associated Ankrd26 mutant protein. The molecular reason for this functional impairment was the deletion of the amphipathic $\mathrm{N}$ terminus of Ankrd26, which we demonstrated to insert itself into the hydrophobic part of the membrane, as demonstrated by its insensitivity to suppression of electrostatic interactions and by mutagenesis of hydrophilic and hydrophobic amino acid residues, respectively. Ankrd26 thus shares some properties with ankycorbin, the founding member of the recently suggested superfamily of N-Ank proteins (Wolf et al, 2019). Within the N- 
Ank superfamily, Ankrd26 phylogenetically belongs to a mostly human or primate-specific subfamily, whose functions are mostly completely unknown.

The ANKRD26 mutant identified in AML (Marconi et al, 2017) was unveiled to be a clear loss-offunction mutant in terms of Ankrd26's N-Ank module-mediated membrane binding. Therefore, impairment of the discovered membrane anchoring and the resulting lack of spatial confinement to the plasma membrane of Ankrd26 seems to be a major aspect of the derailed signaling leading to AML. Ankrd26 also was reported to be involved in the organization of distal appendages of parent centrioles (Evans et al, 2021; Burigotto et al, 2021). Distal appendages are required for basal body docking to the plasma membrane and thereby enable ciliogenesis (Tanos et al, 2013). While the exact role of Ankrd26 in centriolar and/or ciliary functions remains somewhat elusive, as neither ciliogenesis nor centriole duplication was disrupted in cells lacking Ankrd26 (Yan et al, 2020; Evans et al, 2021; Burigotto et al, 2021), at least Ankrd26's role in gating ciliary entry of receptors when additionally the centrosomal protein TALPID3 was knocked down (Yan et al, 2020) may relate to the membrane association of Ankrd26 we identified. It needs to be noted that Ankrd26's localization is not restricted to centrosomes. Ankrd26 was shown to be present throughout the soma of cells (Acs et al, 2015) and we demonstrated that Ankrd26 in fact localizes to large areas of the plasma membrane. As tumor cells frequently show dysregulated centriole numbers (either loss or extra copies) (Nigg and Holland, 2018), it seems possible that ciliary length alterations described in mice expressing a $\beta$-galactosidase gene trap fusion of Ankrd26 may in fact mostly relate to altered signaling pathways. In line with this, these Ankrd26 mutant mice were obese and much larger than WT mice and for some reasons showed increased Akt, mTOR, insulin receptor and insulin growth factor 1 receptor signaling (Bera et al, 2008).

Our analyses of Ankrd26-related pathomechanisms demonstrated that not only Ankrd26's membrane interaction is an important aspect but that Ankrd26 also is able to self-associate. RET is a plasma 
membrane-localized receptor tyrosine kinase connected to a variety of down-stream signaling pathways controlling cellular proliferation (Morandi et al, 2010; Shaw et al, 2013; Mulligan, 2014; Salvatore et al, 2021). Plasma membrane anchoring of RET is mediated by the RET transmembrane domain lacking in the Ankrd26-RET fusion. Furthermore, ligand-induced multisubunit receptor complex formation, which is normally mediated by extracellular interactions, is required for efficient activation of RET signaling (Morandi et al, 2010; Shaw et al, 2013; Mulligan, 2014; Salvatore et al, 2021). Since the RET piece of the Ankrd26-RET fusion solely represents the intracellular kinase domain of RET (Staubitz et al, 2019), also this important aspect in RET functions is disrupted in the RET fragment included in the Ankrd26-RET fusion product found in papillary thyroid carcinoma patients. Our results show that the papillary thyroid carcinoma-associated Ankrd26-RET fusion obviously does have both of these capabilities. Efficient membrane targeting was ensured by Ankrd26's N-Ank module and self-association was brought about by the part of the coiled coil domain of Ankrd26 that surprisingly was sufficient for complex formation.

In the papillary thyroid carcinoma-associated Ankrd26-RET fusion, the combination of both Ankrd26 properties was able to elicit RET autophosphorylation. RET signaling, which is thought to be organized in lipid rafts as signaling hubs (Tansey et al, 2000), thus seems to be successfully mimicked by Ankrd26-RET and by the Ankrd26 properties we identified. As a membrane binding protein, Ankrd26 mimics the membrane association of RET in a very effective, probably constitutive manner when a fragment of Ankrd26 including the membrane-binding $\mathrm{N}$-Ank module fused to the RET kinase domain. Since also Ankrd26-mediated self-association is very effective in the fusion mutant, both key aspects normally controlling RET autophosporylation and signaling are strongly active.

Strikingly, we did not only observe that the Ankrd26 part of the Ankrd26-RET fusion can mimic RET functions successfully but that the association of the Ankrd26-RET fusion mutant with papillary thyroid carcinoma reflects an about five times as high as autophosphorylation when compared to full- 
length RET. Therefore, the Ankrd26-RET fusion mutation represents a completely derailed RET signaling because it was both grossly exaggerated and furthermore completely decoupled from any extracellular ligand binding.

Ankrd26, as a member of the novel N-Ank superfamily, thus is able to self-associate, to insert itself into the cytosolic membrane leaflet of the plasma membrane by amphipathic interactions and to shape membranes into convex membrane topologies by the use of its ankyrin repeat array. The resulting Ankrd26-mediated organizational platforms seem to be of utmost importance for signaling pathways originating from the plasma membrane, which, if derailed, lead to cancer-associated pathomechanisms involving the Ankrd26 properties we identified. 


\section{Material and Methods}

\section{DNA constructs}

Plasmids encoding human Ankrd26-GFP were cloned by PCR using EST clone 6830677 (NM_014915.2) as template and subcloned into pEGFP-N3 (Clontech) using KpnI und BamHI as restriction sites. Human Ankrd26 deletion mutants were generated by PCR introducing appropriate stop codons and restriction sites. These mutants included the Ankrd26 N-Ank module (Ankrd26 ${ }^{\mathrm{N}-\text { Ank }}$ GFP) (aa1-217), an N terminally shortened version only comprising the ankyrin repeats, Ankrd26 ${ }^{\text {Ank }}$ GFP (aa45-217), Ankrd26* AML (aa78-217), Ankrd26 ${ }^{490-1710}$-GFP, Ankrd26 ${ }^{1-1405}$-GFP and Ankrd26 $6^{490-}$ ${ }^{1405}$ _GFP. For full primer list please see Table S1.

Mouse Ankrd26 ${ }^{\mathrm{N}-\mathrm{Ank}}$-GFP (aa1-208) and an N terminally deleted construct (Ankrd26 ${ }^{\text {Ank }}$-GFP (aa11208) were cloned from cDNA prepared from brain of 8 weeks old mice. RNA isolation and reverse transcription PCRs were done according to procedures described previously (Haag et al, 2012). For primers used see Table S1.

Plasmids encoding for GST-fused, WT and mutant Ankrd26 N-Ank modules were generated by cloning into pGEX-6P-1 (GE Healthcare). Forward primers encoding for Ankrd26 point mutants in the amphipathic $\mathrm{N}$ terminus were 5'-ataGGATCCatgaagaaggaagaaagtaag-3' (for generation of

I4E,F5E mutation) and 5'ataGGATCCatggcggcgatttttagtgcggcgggcgagtcgccttgggctccttcgcggcggcgcaggcgagcagcgcggg-3' (for generation of K2A,K3A,K7A,K8A,R18A,R19A,R21A mutation).

Human RET-GFP and RET ${ }^{712-1114}$-GFP were cloned by PCR using a cDNA clone (GenScript Biotech; NM_020975.6) as template. The PCR products were inserted into pEGFP-N1. For full primer list please see Table S1.

Human Ankrd26 ${ }^{1-1405}$ and $\mathrm{RET}^{712-1114}$ were fused by complementing Ankrd26 ${ }^{1-1405}$ with $\mathrm{RET}^{712-1114}$ using the internal AgeI site of the RET-encoding DNA sequence to yield a fusion protein with an 
amino acid sequence identical to the Ankrd-RET fusion identified in papillary thyroid carcinoma patients (Staubitz et al, 2019). For primers see Table S1.

Correct cloning by PCR was verified by sequencing in all cases.

A vector expressing PM-targeted, farnesylated monomeric Cherry (CherryF) was originally provided by M. Korte (TU Braunschweig, Germany) and has been described before to specifically outline the plasma membrane (Hou et al, 2015; Izadi et al, 2018; Wolf et al, 2019).

\section{Antibodies}

Rabbit anti-Ankrd26 (ab47984) and anti-Cherry (ab167453) antibodies were from Abcam and monoclonal mouse anti-GFP were from Covance (JL-8; RRID AB_10013427). Monoclonal mouse anti- $\beta$-actin antibodies were from Sigma (A5441). Mouse monoclonal anti-RET antibodies were from Santa Cruz (6E4C4; sc-101423) and rabbit anti-pRET(pY905) antibodies were from Cell Signaling Technology (3221).

Secondary antibodies used included DyLight800-conjugated goat anti-rabbit and anti-mouse antibodies $(35571,35521)$ from ThermoFisher Scientific. Further secondary antibodies coupled to IRDye680 and IRDye800, respectively, were from LI-COR Bioscience.

\section{Purification of recombinant proteins and tag cleavage}

GST-tagged fusion protein purification and PreScission Protease (GE) cleavage of pGEX-6P-1encoded GST-fusion proteins was performed at $4^{\circ} \mathrm{C}$ during dialysis against $\mathrm{HN}$ buffer $(150 \mathrm{mM} \mathrm{NaCl}$, 2 mM DTT, 20 mM HEPES pH 7.4) overnight essentially as described (Seemann et al, 2017; Wolf et al, 2019). 
Cleaved off GST and putatively remaining uncut GST-fusion proteins were subsequently removed by affinity purification with glutathione-agarose (Antibodies-Online) and proteins of interest were collected as flow-through by centrifugation.

Protein concentrations were determined by the Bradford method. Successful proteolytic cleavage and protein integrity were verified by SDS-PAGE and Coomassie staining.

\section{Liposome preparation and sizing}

Large unilamellar vesicles LUVs (liposomes) were prepared from Folch fraction I lipids (Sigma Aldrich) essentially as described (Koch et al, 2011). The mean diameters of LUV preparations usually range from 300-550 $\mathrm{nm}$. Therefore, all size determinations and liposome size-changing assays were always performed with full set of conditions and controls in each assay.

Small unilamellar vesicles (SUVs) were generated by sonication of LUVs, as described (Zobel et al, 2015). Briefly, liposomes were sonicated 3 times (50 s each, 1 min pause in between) on ice using an ultrasonicator UP50H (Dr. Hielscher). SUVs prepared under these conditions have a mean diameter of about $50 \mathrm{~nm}$, as determined by electron microscopical examinations (Wolf et al, 2019).

\section{Liposome cosedimentations (membrane binding, salt resistance, curvature sensing of proteins)}

Liposome coprecipitation assays were essentially done as described previously (Wolf et al, 2019). In brief, $4 \mu \mathrm{M}$ of untagged WT Ankrd26 N-Ank modules or to be tested mutant proteins, respectively, in $25 \mu \mathrm{HN}$ buffer were prespun for $5 \mathrm{~min}$ at 200000xg to remove putative precipitates. The supernatant was transferred to a fresh tube and incubated with $50 \mu \mathrm{g}$ of Folch fraction I liposomes $(2 \mathrm{mg} / \mathrm{ml})$ for $30 \mathrm{~min}$ at RT. Liposomes were pelleted by $200000 \mathrm{xg}$ centrifugation $\left(20 \mathrm{~min}, 28^{\circ} \mathrm{C}\right)$. The resulting supernatants $(\mathrm{S})$ were collected immediately. The pellets $(\mathrm{P})$ were resuspended in volumes equal to the supernatant. All fractions were then analyzed by SDS-PAGE and Coomassie staining. Gels were 
visualized with a LI-COR Odyssey imager and the lane intensities quantified using the LI-COR Odyssey software (LI-COR Bioscience).

The amount of protein coprecipitated with liposomes was expressed as percent of total protein after subtraction of any putative unspecific background of precipitation in $\mathrm{HN}$ buffer control, i.e. liposome binding $[\%]=[((\mathrm{P} /(\mathrm{S}+\mathrm{P}))$ Sample $-(\mathrm{P} /(\mathrm{S}+\mathrm{P})) \mathrm{HN}$ buffer control $)] \times 100$.

Salt extraction experiments were essentially performed as described above, except that 5 min prior to centrifugation at $200000 \mathrm{xg}$ the final $\mathrm{NaCl}$ concentration was increased from $150 \mathrm{mM}$ ( $\mathrm{HN}$ buffer) to $200 \mathrm{mM}$ and $250 \mathrm{mM}$, respectively.

Curvature sensing activities were analyzed by slightly modified cosedimentation assays using LUVs versus SUVs, as essentially described previously (Wolf et al, 2019). Due to decreased sedimentation efficiencies of SUVs and the accordingly lose pellets, only the upper $35 \mu$ of the $200000 \times \mathrm{xg}$ centrifugation supernatant were collected and supplemented with 4x SDS-PAGE sample buffer yielding $47 \mu \mathrm{l}$ of sample. For direct comparison, the pellet-containing fraction was also resuspended in a final volume of $47 \mu$. Both samples were then analyzed by SDS-PAGE and Coomassie staining. The signals were quantified and, as in LUV binding experiments described above, traces of protein precipitating in control incubations without any liposomes added were subtracted from the data of liposome binding as unspecific background. The data were then expressed as deviation of SUV binding from LUV binding.

\section{Freeze-fracturing and TEM of freeze-fracture replica}

For determinations of size changes of liposomes by Ankrd26 proteins, $100 \mu \mathrm{g}$ liposomes were incubated with a final protein concentration of $6 \mu \mathrm{M}$ Ankrd26 N-Ank module and mutants thereof, respectively, in a final volume of $100 \mu \mathrm{l}$ for $15 \mathrm{~min}$ at $37^{\circ} \mathrm{C}$. To avoid liposomal aggregation during sample preparation, the suspension was subsequently incubated with $30 \mu \mathrm{g}$ proteinase $\mathrm{K}$ for 25 min at 
$45^{\circ} \mathrm{C}$. Liposomes were centrifuged for $15 \mathrm{~min}$ at $200000 \mathrm{xg}$ and the pellet was resuspended in $20 \mu 1$ of the supernatant to obtain a concentrated liposome preparation for freeze-fracture (Beetz et al, 2013).

Freeze-fracturing of liposomes was done using $0.6 \mathrm{~mm}$ high copper profiles essentially as described previously (Seemann et al, 2017; Wolf et al, 2019). Copper profiles were cleaned by sonication with $4 \%(\mathrm{w} / \mathrm{v})$ tartaric acid, washed in pure acetone and stored in pure methanol. $2 \mu$ of the liposome solution was distributed between two copper profiles and the sandwich was immediately plunge frozen in liquid propane:ethane (1:1) cooled in liquid nitrogen. Three sandwiches were placed in a double-replica specimen table cooled by liquid nitrogen that was then transferred into the freezefracture machine BAF400T (Leica) cooled to $-140^{\circ} \mathrm{C}$. After the vacuum was established $\left(\leq 10^{-6} \mathrm{mbar}\right)$, the table was flipped open separating the two sandwiched profiles and freeze-fracturing the sample.

Immediately thereafter, $2 \mathrm{~nm}$ platinum/carbon was evaporated onto the samples (angle, $35^{\circ}$ ). The replica were then stabilized by evaporating a carbon coat of $15-20 \mathrm{~nm}$ onto the samples (angle, $90^{\circ}$ ). The samples were then carefully extracted from the freeze-fracture machine, thawed and floated onto $\mathrm{ddH}_{2} \mathrm{O}$. Replica were then incubated for $15 \mathrm{~min}$ in $3 \%(\mathrm{v} / \mathrm{v})$ sodium hypochlorite warmed to $50^{\circ} \mathrm{C}$, washed twice with $\mathrm{ddH}_{2} \mathrm{O}$ for $10 \mathrm{~min}$, transferred onto uncoated copper grids (300 mesh) and dried.

Replica of freeze-fractured liposomes were analyzed by TEM. The electron microscope (EM902A, Zeiss) was operated at $80 \mathrm{keV}$.

Imaging was done by systematic explorations of the grids. Images were recorded with a CCD camera (TVIPS; EM-Menu 4) and processed with Adobe Photoshop.

\section{Quantitative EM analyses}

Diameters of freeze-fractured liposomes were measured using ImageJ, as described previously (Wolf et al, 2019). Irregular structures were excluded from analysis.

All TEM studies were conducted in a fully blinded manner. 


\section{Culturing, transfection, immunostaining and fluorescence microscopy of cells}

Culturing of HEK293 and HeLa cells and their transfection using TurboFect (ThermoFisher Scientific) was essentially done as described (Kessels et al, 2001; Haag et al, 2012).

Images were recorded using a Zeiss AxioObserver.Z1 microscope equipped with an ApoTome for pseudo-confocal image recording (Zeiss), Plan-Apochromat 63x/1.4, and 40x/1.3 objectives (Zeiss) and an AxioCam MRm CCD camera (Zeiss).

Digital images from Zeiss microscopes were recorded by ZEN2012. Image processing was done by Adobe Photoshop.

\section{Preparation of membrane-enriched fractions from HEK293 cells}

HEK293 cells were transfected and 24 h post transfection, the cells were washed with PBS, harvested, collected by centrifugation $\left(1000 \mathrm{xg} 5 \mathrm{~min}, 4^{\circ} \mathrm{C}\right)$, resuspended in homogenization buffer $(0.32 \mathrm{M}$ sucrose, $5 \mathrm{mM}$ HEPES pH 7.4, 1 mM EDTA) containing protease inhibitor Complete (Roche) and then homogenized by multiple passing through a $0.24 \mathrm{~mm}$ syringe.

The resulting homogenates were fractionated essentially as described (Wolf et al, 2019). In brief, the homogenates were subjected to centrifugation at $4{ }^{\circ} \mathrm{C}$ for $10 \mathrm{~min}$ at $1000 \mathrm{xg}$ yielding fractions $\mathrm{S} 1$ and P1. S1 was then centrifuged further for $20 \mathrm{~min}$ at $118000 \mathrm{xg}$. After removal of the supernatant S2, the resulting membrane-containing pellet $\mathrm{P} 2$ was resuspended in homogenization buffer und again centrifuged at $11800 \mathrm{xg}$ for 20 min resulting in fractions S2' and P2'. P2' thus represents a washed membrane-containing fraction $\mathrm{P} 2$.

All pellet fractions were resuspended in volumes equal to those of the corresponding supernatants. SDS-PAGE was performed with equal amounts of supernatant and pellet fractions and analyzed by 
(quantitative) immunoblotting using a LI-COR Odyssey System for fluorescence detection and Image Studio Lite V5.2 for band intensity determinations (LI-COR Biosciences GmbH).

\section{Crosslink studies}

Crosslink studies with lysates of HEK293 cells overexpressing different GFP fusion proteins were essentially done as described for endogenous proteins (Kessels and Qualmann, 2006). The cell lysates were incubated in the presence of increasing amounts of the heterobifunctional crosslinker 1-ethyl-3[dimethylaminopropyl]carbodiimide (EDC) (Pierce) in $20 \mathrm{mM}$ HEPES, $\mathrm{pH} 7.4,0.2 \mathrm{mM} \mathrm{MgCl}$, and 2 $\mathrm{mM}$ EGTA for $20 \mathrm{~min}$ at $30^{\circ} \mathrm{C}$. Subsequently, the crosslinking reaction was stopped by adding $4 \mathrm{x}$ SDS-PAGE sample buffer and incubating the samples at $95^{\circ} \mathrm{C}$ for $5 \mathrm{~min}$. The samples then were analyzed by immunoblotting (tank blotting to PVDF membranes).

\section{RET signaling activity determinations by quantitative immunodetection of RET Y905}

\section{phosphorylation}

HEK293 cells were transfected with GFP-tagged RET fragment RET ${ }^{712-1114}$, full-length RET and the Ankrd26 ${ }^{1-1405}-\mathrm{RET}^{712-1114}$ fusion mutant, respectively, and harvested $48 \mathrm{~h}$ later. Cell lysis was conducted in radioimmunoprecipitation (RIPA) buffer $\left(150 \mathrm{mM} \mathrm{NaCl}, 10 \mathrm{mM} \mathrm{Na} 3 \mathrm{PO}_{4} \mathrm{pH} 7.2,1 \%\right.$ (w/w) Nonidet P-40, 0.5\% (w/v) sodium desoxycholate, $2 \mathrm{mM}$ EDTA, $50 \mathrm{mM} \mathrm{NaF}$, protease inhibitor cocktail Complete EDTA-free (Roche), phosphatase inhibitor cocktail PhosSTOP (Roche)) for 20 min at $4^{\circ} \mathrm{C}$ and by sonication ( 5 pulses of each $1 \mathrm{~s}$ ). The lysates were centrifuged at $10000 \mathrm{xg}$ for $10 \mathrm{~min}$ at $4^{\circ} \mathrm{C}$. The supernatants were combined, incubated at $95^{\circ} \mathrm{C}$ with SDS-PAGE sample puffer for 5 min and immunoblotted for analyses of GFP and RET, respectively (determination of expression levels) and for pRET (pY905) to determine the autophosphorylation of RET as a measure for the RET signaling activities of the different, to be analyzed proteins in relation to their expression levels. The immunosignals were quantitatively analyzed using a LI-COR Odyssey System. 


\section{In silico analyses}

Amphipathic helical wheel representations were done using HELIQUEST (Gautier et al, 2008). The ankyrin repeat array of human Ankrd26 was modelled in two rotational views employing https://swissmodel.expasy.org/viewer/ngl/. Coiled coil predictions were done with COILS. (https://www.expasy.org/resources/coils). Alignments were done using Clustal Omega (https://www.ebi.ac.uk/Tools/msa/clustalo/).

\section{Data reporting and statistical analyses}

No statistical methods were used to predetermine sample size. All TEM experiments were randomized and the investigators were blinded to allocation during experiments and outcome assessment.

No outlier suggestions were computed. All quantitative evaluation data points were taken into account and averaged to fully represent biological and technical variabilities. Wherever useful, i.e. in all but three panels, the bar plots in the figures have been overlayed with dot plots showing all individual data points measured .

All quantitative data shown represent mean and SEM. Statistical analyses were done using GraphPad Prism software. Statistical significances were marked by $* P<0.05 ; * * P<0.01 ; * * * P<0.001$; $* * * * P<0.0001$ throughout.

Determinations of liposome binding, SUV versus LUV preference in binding as well as differences in liposome diameters were analyzed for significances by either Mann-Whitney-U-test or two-tailed, unpaired Student's t-test (depending on normal data distribution; comparisons of two conditions) or by two-way ANOVA or by Kruskal Wallis (multiple conditions), respectively.

Quantitative data from extractions of liposome-bound proteins with salt were tested using one-way ANOVA with Tukey post hoc test. 
bioRxiv preprint doi: https://doi.org/10.1101/2021.05.19.444897; this version posted May 20, 2021. The copyright holder for this preprint (which

was not certified by peer review) is the author/funder, who has granted bioRxiv a license to display the preprint in perpetuity. It is made available under aCC-BY-NC-ND 4.0 International license.

Determinations of the pY905 autophosphorylation levels of RET, RET ${ }^{712-1114}$ and the Ankrd26-RET fusion mutant were tested by Kruskal Wallis and Dunn's multiple comparison post test.

\section{Data availability}

This study includes no data deposited in external repositories. 


\section{Acknowledgments}

We thank D. Wolf for valuable initial observations. We furthermore thank B. Schade, M. Roeder and

S. Linde for technical assistance, E. Seemann for EM instructions and advice and M. Westermann for access to freeze-fracturing and TEM.

This work was supported by an IZFK (Interdisziplinäres Zentrum für Klinische Forschung) grant to M.M.K. (RTG1715) and by a DFG grant to B.Q. (QU116/9-1), respectively.

\section{Author contributions}

S.A.H.-M. and K.L.M. performed experiments. S.A.H.-M., M.M.K. and B.Q. designed experiments and evaluated data. S.A.H.-M. co-wrote the manuscript. M.M.K. and B.Q. conceived the project and wrote the manuscript.

\section{Conflict of interests}

The authors declare no competing financial interests. 


\section{References}

Acs P, Bauer PO, Mayer B, Bera T, Macallister R, Mezey E, Pastan I. A novel form of ciliopathy underlies hyperphagia and obesity in Ankrd26 knockout mice. Brain Struct Funct 220: 1511-1528

Beetz C, Koch N, Khundadze M, Zimmer G, Nietzsche S, Hertel N, Huebner AK, Mumtaz R, Schweizer M, Dirren E, Karle KN, Irintchev A, Alvarez V, Redies C, Westermann M, Kurth I, Deufel T, Kessels MM, Qualmann B, Hübner CA (2013) A spastic paraplegia mouse model reveals REEP1dependent ER shaping. J Clin Invest 123: 4273-4282

Bera TK, Zimonjic DB, Popescu NC, Sathyanarayana BK, Kumar V, Lee B, Pastan I (2002) POTE, a highly homologous gene family located on numerous chromosomes and expressed in prostate, ovary, testis, placenta, and prostate cancer. Proc Natl Acad Sci U S A. 99: 16975-16980

Bera TK, Saint Fleur A, Lee Y, Kydd A, Hahn Y, Popescu NC, Zimonjic DB, Lee B, Pastan I (2006) POTE paralogs are induced and differentially expressed in many cancers. Cancer Res 66: 52-56

Bera TK, Liu XF, Yamada M, Gavrilova O, Mezey E, Tessarollo L, Anver M, Hahn Y, Lee B, Pastan I (2008) A model for obesity and gigantism due to disruption of the Ankrd26 gene. Proc Natl Acad Sci U S A 105: 270-275

Bluteau D, Balduini A, Balayn N, Currao M, Nurden P, Deswarte C, Leverger G, Noris P, Perrotta S, Solary E, Vainchenker W, Debili N, Favier R, Raslova H (2014) Thrombocytopenia-associated mutations in the ANKRD26 regulatory region induce MAPK hyperactivation. J Clin Invest 124: 58091

Burigotto M, Mattivi A, Migliorati D, Magnani G, Valentini C, Roccuzzo M, Offterdinger M, Pizzato M, Schmidt A, Villunger A, Maffini S, Fava LL (2021) Centriolar distal appendages activate the centrosome-PIDDosome-p53 signalling axis via ANKRD26. EMBO J 40: e104844

Cerami E, Gao J, Dogrusoz U, Gross BE, Sumer SO, Aksoy BA, Jacobsen A, Byrne CJ, Heuer ML, Larsson E, Antipin Y, Reva B, Goldberg AP, Sander C, Schultz N (2012) The cBio cancer genomics portal: an open platform for exploring multidimensional cancer genomics data. Cancer Discov 2: 401404

Evans LT, Anglen T, Scott P, Lukasik K, Loncarek J, Holland AJ (2021) ANKRD26 recruits PIDD1 to centriolar distal appendages to activate the PIDDosome following centrosome amplification. EMBO J 40: e105106

Fava LL, Schuler F, Sladky V, Haschka MD, Soratroi C, Eiterer L, Demetz E, Weiss G, Geley S, Nigg EA, Villunger A (2017) The PIDDosome activates p53 in response to supernumerary centrosomes. Genes Dev 31: 34-45

Gautier R, Douguet D, Antonny B, Drin G (2008) HELIQUEST: a web server to screen sequences with specific alpha-helical properties. Bioinformatics 24: 2101-2102

Haag N, Schwintzer L, Ahuja R, Koch N, Grimm J, Heuer H, Kessels MM, Qualmann B (2012) The actin nucleator Cobl is crucial for Purkinje cell development and works in close conjunction with the F-actin binding protein Abp1. J Neurosci 32: 17842-17856 
Hou W, Izadi M, Nemitz S, Haag N, Kessels MM, Qualmann B (2015) The actin nucleator Cobl is controlled by calcium and calmodulin. PLoS Biol 13: e1002233

Izadi M, Schlobinski D, Lahr M, Schwintzer L, Qualmann B, and Kessels MM (2018) Cobl-like promotes actin filament formation and dendritic branching using only a single WH2 domain. J Cell Biol 217:211-230

Kessels MM, Qualmann B (2006) Syndapin oligomers interconnect the machineries for endocytic vesicle formation and actin polymerization. J Biol Chem 281: 13285-13299.

Kessels MM, Engqvist-Goldstein AEY, Drubin DG, Qualmann B (2001) Mammalian Abp1, a signalresponsive F-actin-binding protein, links the actin cytoskeleton to endocytosis via the GTPase dynamin. J Cell Biol 153: 351-366

Koch D, Spiwoks-Becker I, Sabanov V, Sinning A, Dugladze T, Stellmacher A, Ahuja R, Grimm J, Schüler S, Müller A, Angenstein F, Ahmed T, Diesler A, Moser M, Tom Dieck S, Spessert R, Boeckers TM, Fässler R, Hübner CA, Balschun D, Gloveli T, Kessels MM, Qualmann B (2011) Proper synaptic vesicle formation and neuronal network activity critically rely on syndapin I. EMBO J 30: 4955-4969.

Liu M, Chen P, Hu HY, Ou-Yang DJ, Khushbu RA, Tan HL, Huang P, Chang S (2021) Kinase gene fusions: roles and therapeutic value in progressive and refractory papillary thyroid cancer. $J$ Cancer Res Clin Oncol 147: 323-337.

Marconi C, Canobbio I, Bozzi V, Pippucci T, Simonetti G, Melazzini F, Angori S, Martinelli G, Saglio G, Torti M, Pastan I, Seri M, Pecci A (2017) 5'UTR point substitutions and N-terminal truncating mutations of ANKRD26 in acute myeloid leukemia. J Hematol Oncol 10: 18

Morandi A, Plaza-Menacho I, Isacke CM (2011) RET in breast cancer: functional and therapeutic implications. Trends Mol Med 17: 149-157

Mosavi LK, Cammett TJ, Desrosiers DC, Peng ZY (2004) The ankyrin repeat as molecular architecture for protein recognition. Protein Sci 13: 1435-1448

Mulligan LM (2014) RET revisited: expanding the oncogenic portfolio. Nat Rev Cancer 14: 173-186

Nigg EA, Holland AJ (2018) Once and only once: mechanisms of centriole duplication and their deregulation in disease. Nat Rev Mol Cell Biol 19: 297-312

Noris P, Perrotta S, Seri M, Pecci A, Gnan C, Loffredo G, Pujol-Moix N, Zecca M, Scognamiglio F, De Rocco D, Punzo F, Melazzini F, Scianguetta S, Casale M, Marconi C, Pippucci T, Amendola G, Notarangelo LD, Klersy C, Civaschi E, Balduini CL, Savoia A (2011) Mutations in ANKRD26 are responsible for a frequent form of inherited thrombocytopenia: analysis of 78 patients from 21 families. Blood 117: 6673-6680

Pippucci T, Savoia A, Perrotta S, Pujol-Moix N, Noris P, Castegnaro G, Pecci A, Gnan C, Punzo F, Marconi C, Gherardi S, Loffredo G, De Rocco D, Scianguetta S, Barozzi S, Magini P, Bozzi V, Dezzani L, Di Stazio M, Ferraro M, Perini G, Seri M, Balduini CL (2011) Mutations in the 5' UTR of ANKRD26, the ankirin repeat domain 26 gene, cause an autosomal-dominant form of inherited thrombocytopenia, THC2. Am J Hum Genet 88: 115-120 
Redfield SM, Mao J, Zhu H, He Z, Zhang X, Bigler SA, Zhou X (2013) The C-terminal common to group 3 POTES (CtG3P): a newly discovered nucleolar marker associated with malignant progression and metastasis. Am J Cancer Res 3: 278-289

Salvatore D, Santoro M, Schlumberger M (2021) The importance of the RET gene in thyroid cancer and therapeutic implications. Nat Rev Endocrinol 17: 296-306

Seemann E, Sun M, Krueger S, Tröger J, Hou W, Haag N, Schüler S, Westermann M, Huebner CA, Romeike B, Kessels MM, Qualmann B (2017) Deciphering caveolar functions by syndapin III KOmediated impairment of caveolar invagination. eLife 6: pii: e29854

Shaw AT, Hsu PP, Awad MM, Engelman JA. (2013) Tyrosine kinase gene rearrangements in epithelial malignancies. Nat Rev Cancer 13: 772-787

Staubitz JI, Musholt TJ, Schad A, Springer E, Lang H, Rajalingam K, Roth W, Hartmann N. (2019) ANKRD26-RET - A novel gene fusion involving RET in papillary thyroid carcinoma. Cancer Genet 238: $10-17$

Takahashi M, Cooper GM (1987) ret transforming gene encodes a fusion protein homologous to tyrosine kinases. Mol Cell Biol 7: 1378-1385

Tanos BE, Yang HJ, Soni R, Wang WJ, Macaluso FP, Asara JM, Tsou MF (2013) Centriole distal appendages promote membrane docking, leading to cilia initiation. Genes Dev 27: 163-168

Tansey MG, Baloh RH, Milbrandt J, Johnson EM Jr (2000) GFRalpha-mediated localization of RET to lipid rafts is required for effective downstream signaling, differentiation, and neuronal survival. Neuron 25: 611-623

Wolf D, Hofbrucker-MacKenzie SA, Izadi M, Seemann E, Steiniger F, Schwintzer L, Koch D, Kessels MM, Qualmann B (2019) Ankyrin repeat-containing N-Ank proteins shape cellular membranes. Nat Cell Biol 21: 1191-1205

Yan H, Chen C, Chen H, Hong H, Huang Y, Ling K, Hu J, Wei Q. (2020) TALPID3 and ANKRD26 selectively orchestrate FBF1 localization and cilia gating. Nat Commun 11: 2196

Zobel T, Brinkmann K, Koch N, Schneider K, Seemann E, Fleige A, Qualmann B, Kessels MM, Bogdan S. (2015) Cooperative functions of the two F-BAR proteins Cip4 and Nostrin in the regulation of E-cadherin in epithelial morphogenesis. J Cell Sci 128: 1453 


\section{Figure Legends}

Fig 1. Ankrd26 is a plasma membrane-binding protein using an N-Ank module for membrane association.

(A,B) Subcellular fractionations of human (hu) Ankrd26-GFP- and GFP-transfected HEK293 cells coexpressing CherryF. Arrowheads highlight proteins detected in P2 and P2' membrane fractions. CherryF represents plasma membrane-integrated proteins; endogenous $\beta$-actin represents cell cortexassociated and cytosolic proteins. (C,D) Maximum intensity projections (MIPs) of Ankrd26-GFP and GFP in HeLa cells cotransfected with the plasma membrane marker CherryF with intensity plots of the red and green fluorescent channel along the randomly positioned lines marked in the insets (magnifications of boxed areas). Bars, $10 \mu \mathrm{m}$. (E) Schematic representation of human (hu) Ankrd26 (UniProt Q9UPS8) with its $\mathrm{N}$ terminal domain appearing to be an N-Ank module, which according to UniProt contains five ankyrin repeats (see Fig EV1 for comparison of all five suggested repeats with a general ankyrin repeat consensus sequence). (F-M) In silico analyses of putative amphipathic structures at the $\mathrm{N}$ termini of human $(\mathbf{F})$ and mouse (ms) Ankrd26 (J) (helical wheel representations using HELIQUEST; amino acid color coding: blue, positively charged; yellow, hydrophobic; grey, other) and representative example images of Coomassie-stained SDS-PAGE analyses of liposome coprecipitation studies ( $\mathrm{S}$, supernatant; $\mathrm{P}$, pellet) demonstrating a membrane binding of recombinant purified human and mouse Ankrd26 (UniProt D3Z482) N-Ank modules (Ankrd26 $6^{\mathrm{N}-A n k}$ ) and deletion mutants thereof comprising only the ankyrin repeat arrays (Ankrd26 ${ }^{\text {Ank }}$ ), i.e. lacking the putative amphipathic structures at the $\mathrm{N}$ termini $(\mathbf{G}, \mathbf{H}, \mathbf{K}, \mathbf{L})$ as well as corresponding quantitative analyses of liposome binding (I,M). Data represent mean \pm standard error of means (SEM) of quantitative analyses with two independent liposome preparations ( $\mathrm{n}=6$ experiments each condition). Shown are bar plots with individual data points (dot plots). Unpaired Student's t-test. $* * * * P<0.0001$. (N,O) Analysis of 
the localization of Ankrd26 $6^{\mathrm{N}-\mathrm{Ank}}(\mathbf{N})$ and of the Ankrd26 ${ }^{\text {Ank }}$ deletion mutant $(\mathbf{O})$ in HeLa cells coexpressing CherryF. Insets represent magnifications of boxed areas. Bars, $10 \mu \mathrm{m}$.

Fig 2. An $\mathbf{N}$ terminal truncation of the suggested $\mathbf{N}$-Ank module of Ankrd26 found in AML patients completely disrupts membrane binding in vitro and in vivo

(A) Schematic representation of the ankyrin repeats-containing $\mathrm{N}$ termini of human Ankrd26 and of a corresponding mutant found in AML patients, which results in an $\mathrm{N}$ terminally truncated protein (Ankrd26 ${ }^{78-217} ;$ Ankrd26* AML $)$. (B-D) Representative images of Coomassie-stained gels of liposome coprecipitation analyses with Ankrd26 ${ }^{\mathrm{N}-\mathrm{Ank}}$ and Ankrd26* AML (side-by-side analyses using the same preparation of liposomes) (B,C) and quantitative liposome binding evaluations thereof (D). (E,F) Immunoblotting analyses of subcellular fractionations of lysates of HEK293 cells that were transfected with Ankrd26* AML-GFP (E) and Ankrd26 ${ }^{\mathrm{N}-\mathrm{Ank}}$-GFP (F), respectively, and coexpressed CherryF. Arrowheads highlight proteins detected in P2 and P2' membrane fractions (WT Ankrd26 ${ }^{\mathrm{N}-}$ Ank and CherryF only). (G) MIP showing a lacking plasma membrane localization of Ankrd26* AML_ GFP in HeLa cells coexpressing CherryF. Bars, $10 \mu \mathrm{m}$. Data, mean \pm SEM. Quantitative analyses with two independent liposome preparations ( $\mathrm{n}=6$ experiments each condition) (D). Bar plots with individual data points (dot plots). Two-tailed, unpaired Student's t-test. $* * * * P<0.0001$.

Fig 3. Ankrd26 is an N-Ank protein recognizing membrane curvature by ankyrin repeat arrays and shaping membrane topology by combination with a membrane-inserted amphipathic structure

(A-D) Representative images of Coomassie-stained SDS-PAGE gels $(\mathbf{A}, \mathbf{C})$ of attempts of extraction of liposome-bound human Ankrd26 $6^{\mathrm{N}-\mathrm{Ank}}(\mathbf{A}, \mathbf{B})$ and the corresponding Ankrd26 ${ }^{\text {Ank }}$ deletion mutant (C,D) by increasing salt concentrations (S, supernatant; P, pellet) and quantitative analyses thereof 
showing that the liposome binding of Ankrd26 $6^{\mathrm{N}-\mathrm{Ank}}$ is fully salt-resistant, whereas the weaker membrane association of Ankrd26 ${ }^{\text {Ank }}$ was merely based on electrostatic interactions suppressible by increasing salt (B,D). (E) Alignment of the $\mathrm{N}$ termini of rat (rt; UniProt, M0R3T8), mouse (ms; UniProt, D3Z482) and human (hu; UniProt, Q9UPS8) Ankrd26 with a high conservation of both hydrophobic (residues mutated highlighted in dark yellow) and positively charged (residues mutated highlighted in blue) amino acids. (F-K) Liposome binding analyses with mutant N-Ank modules of Ankrd26 with either two hydrophobic residues turned into hydrophilic ones (Ankrd26 ${ }^{\mathrm{N}-A n k}$ I4E,F5E $)$ and with all positive residues of the Ankrd26 $\mathrm{N}$ terminal sequence erased (Ankrd26 ${ }^{\mathrm{N}-A n k}$

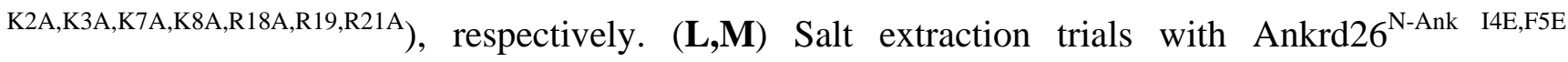
demonstrating a disruption of the salt resistance of the membrane binding of Ankrd26's N-Ank module by mutating isoleucine 4 and phenylalanine 5. (N) The ankyrin repeat array of human Ankrd26 in two rotational views (modelling, https://swissmodel.expasy.org/viewer/ngl/; Y40 blue to V208 red). (O-R) Liposome coprecipitation studies $(\mathbf{O}, \mathbf{Q})$ with the wild type Ankrd26's ankyrin repeat array and an AML-associated mutant N-Ank module Ankrd26* AML, respectively, with LUVs versus SUVs unveiling that the ankyrin repeat array of Ankrd26 prefers highly curved membranes $(\mathbf{O}, \mathbf{P})$ - a property preserved in the ankyrin repeat part of the AML-associated mutant of Ankrd26 $(\mathbf{Q}, \mathbf{R})$ - and quantitative comparisons thereof $(\mathbf{P}, \mathbf{R})$. (S-X) Representative TEM images of freezefractured liposomes incubated with HN buffer (buffer control) (S), GST as an unrelated protein control (T), ms Ankrd26 ${ }^{\mathrm{N}-\mathrm{Ank}}$ shaping liposomes to smaller structures (arrowheads) (U) or ms Ankrd26 ${ }^{\text {Ank }}(\mathbf{V})$ and quantitative analyses of mean liposome diameters $(\mathbf{W})$ as well as distribution analysis of liposome diameters $(\mathbf{X})$ (data range shown, 0 to $300 \mathrm{~nm}$ ). Bars in $\mathbf{S}-\mathbf{V}, 200 \mathrm{~nm}$. Colored areas in $\mathbf{X}$ mark overrepresentations of smaller liposomes upon incubation with Ankrd26 ${ }^{\mathrm{N}-\mathrm{Ank}}$ when compared to all other curves (green) and to all except one of the other curves (lighter shade of green), respectively. Data represent mean \pm SEM. (B,D,H,K,M,P,R) Bar plots with individual data points (dot 
plots). (B) n=5 assays; (D,H,K,M,P,R) n=6 assays each. (B,D,M) one-way ANOVA with Tukey post hoc test; (H,K,P,R) two-tailed, unpaired Student's t-test. (W) n=512 (buffer control); n=506 (unrelated protein control); $\mathrm{n}=508\left(\mathrm{~ms}\right.$ Ankrd26 $\left.6^{\mathrm{N}-\mathrm{Ank}}\right) ; \mathrm{n}=501\left(\mathrm{~ms}\right.$ Ankrd26 ${ }^{\text {Ank }}$ ) liposomes from two independent experiments and liposome preparations. Kruskal-Wallis test with Dunn's multiple comparison test. $* P<0.05 ; * * P<0.01 ; * * * P<0.001 ; * * * * P<0.0001$.

Fig 4. The papillary thyroid carcinoma-associated fusion of Ankrd26 and RET exhibits a membrane localization mediated by the Ankrd26 portion it includes

(A-H) MIPs of indicated proteins in CherryF-cotransfected HeLa cells (A,C,E,G) and subcellular fractionations of lysates of HEK293 cells expressing the indicated proteins (B,D,F,H). Analyzed were RET-GFP (full-length; aa1-1114) (A,B), the RET fragment RET ${ }^{712-1114}$-GFP (C,D), the Ankrd26 fragment Ankrd26 $6^{1-1405}$-GFP $(\mathbf{E}, \mathbf{F})$ and the papillary thyroid carcinoma-associated fusion Ankrd26 ${ }^{1-}$ ${ }^{1405}{ }^{-R_{E T}}{ }^{712-1114}$-GFP $(\mathbf{G}, \mathbf{H})$. Arrows in A, E and $\mathbf{G}$ mark some examples of colocalization of RETGFP (A), Ankrd26 ${ }^{1-1405}$-GFP (E) and Ankrd26 ${ }^{1-1405}-\mathrm{RET}^{712-1114}-\mathrm{GFP}(\mathbf{G})$, respectively, with the plasma membrane marker CherryF. Bars, $10 \mu \mathrm{m}$. Insets are magnifications of boxed areas highlighting colocalizations with the membrane marker CherryF (A,E,G). Proteins detected in the immunoblotted membrane fractions P2 and P2' are marked by arrowheads (B,D,F,H).

Fig 5. Ankrd26 is able to self-associate and the Ankrd26 fragment included in the Ankrd26 ${ }^{1-1405}$ $\operatorname{RET}^{712-1114}$ fusion mutant found in papillary thyroid carcinoma patients confers this function to the fusion mutant thereby mimicking RET dimerization

$(\mathbf{A}, \mathbf{B})$ Schematic representations of full-length RET and of the papillary thyroid carcinoma-associated Ankrd26-RET fusion (B). TM, transmembrane domain. (C) Schematic representation of human Ankrd26 with its $\mathrm{N}$ terminal $\mathrm{N}$-Ank module and its $\mathrm{C}$ terminal coiled coil domain. Black lines 
represent additional deletion mutants tested for self-association. (D) Coiled coil prediction by COILS (blue). The coiled coil domain part lacking in the papillary thyroid carcinoma-associated fusion with RET is depicted in light blue. (E-L) Immunoblot analyses of experiments without EDC and with increasing concentrations of the crosslinker EDC added to cell lysates containing overexpressed RETGFP (E), the C terminal RET fragment found in papillary thyroid carcinoma patients $\left(\mathrm{RET}^{712-1114}\right)$ (F), full-length Ankrd26-GFP (G), Ankrd26 $6^{1-217}$-GFP encompassing the N-Ank module of Ankrd26 (H), the complete coiled coil domain of Ankrd26 (Ankrd26 $6^{490-1710}$-GFP) (I), the part of Ankrd26 up to the fusion point with RET in papillary thyroid carcinoma (Ankrd26 $\left.6^{1-1405}-\mathrm{GFP}\right)(\mathbf{J})$, and the part of only Ankrd26's coiled coil domain included in the papillary thyroid carcinoma-associated fusion with RET (K). Note the EDC-induced high-molecular weight bands that - except for the N-Ank module of Ankrd26 (Ankrd26 $\left.{ }^{490-1405}\right)(\mathbf{H})$ and the C terminal RET fragment RET ${ }^{712-1114}$ representing merely the kinase domain of RET (F) - occurred with all proteins tested. (L) Crosslink studies with the papillary thyroid carcinoma-associated Ankrd26 $6^{1-1405}-\mathrm{RET}^{712-1114}$ fusion showing that, despite the lack of selfassociation by the RET fragment, fusion to Ankrd26 $6^{1-1405}$ efficiently brings about self-association of the papillary thyroid carcinoma-associated mutant.

\section{Fig 6. The papillary thyroid carcinoma-associated fusion of Ankrd26 and RET exhibits a} strongly increased autophosphorylation of the RET kinase domain

(A-C) Representative images of lysates of HEK293 cells transfected with GFP-tagged RET ${ }^{712-1114}$, full-length RET $\left(\mathrm{RET}^{1-1114}\right)$ and the papillary thyroid carcinoma-associated fusion Ankrd26 $6^{1-1405}$ $\mathrm{RET}^{712-1114}$, respectively, that were immunoblotted with antibodies specifically detecting pRET (pY905) (A), with antibodies against the C terminal domain of RET (B) and with anti-GFP antibodies (C), respectively. Arrowheads mark the positions of the highly Y905 phosphorylated Ankrd26 ${ }^{1-1405}$ RET $^{712-1114}$-GFP. (D,E) Relative quantitative determination of RET activity by anti-Y905 
immunoblotting normalized to expression, as determined by anti-GFP immunoblotting (D) and antiRET immunoblotting (E), respectively. For comparability, anti-pRET/anti-GFP and anti-pRET/antiRET ratios of GFP-tagged RET-GFP, RET $^{712-114}$ and the papillary thyroid carcinoma-associated Ankrd26 $6^{1-1405}-\mathrm{RET}^{712-1114}$ fusion mutant were normalized to the average of the of full-length RETGFP data obtained from each set of assays. Note that the papillary thyroid carcinoma-associated Ankrd26 $6^{1-1405}-\mathrm{RET}^{712-1114}$-GFP mutant showed a RET Y905 autophosphorylation that was 5-7times as high as the autophosphorylations of RET or of the RET kinase domain alone (D,E). Data represent mean \pm SEM. $n=17$ assays each $(\mathbf{D})$ and $n=14(\mathbf{E})$, respectively. Kruskal-Wallis and Dunn's multiple comparison post test. $* P<0.05 ; * * * P<0.001$. 


\section{Legends of Expanded View Figures}

Fig EV1 (related to Fig 1). Human Ankrd26 is a membrane-binding, five ankyrin repeatcontaining protein

$(\mathbf{A , B})$ Maximum intensity projections (MIPs) of Ankrd26-GFP and GFP in HeLa cells cotransfected with the plasma membrane marker CherryF shown in Fig 1C,D with intensity plots of the red and green fluorescent channel along randomly positioned lines marked in the insets, which represent magnifications of boxed areas. Note that in $\mathbf{A}$, both fluorophores show synchronous intensity changes (coenrichment), whereas the control shown in $\mathbf{B}$ does not show any correlation. Bars, $10 \mu \mathrm{m} .(\mathbf{C})$ Ankyrin repeat consensus according to Mosavi et al (2008). (D) The five suggested ankyrin repeats of human Ankrd26 (according to UniProt) and their overlap with the Mosavi consensus. Residues of high, medium and lower conservation in the Mosavi consensus are highlighted in different shades of red, as indicated. Grey marks residues that are not following the consensus and are located between the ankyrin repeats of Ankrd26 (included only to report a continuous sequence of the complete ankyrin repeat array).

\section{Fig EV2 (related to Fig 1). Mouse Ankrd26 ${ }^{\text {N-Ank }}$ but not a mutant lacking Ankrd26's amphipathic $\mathbf{N}$ terminal structure colocalizes with the plasma membrane marker CherryF}

(A-C) Maximum intensity projections (MIPs) of GFP (A), mouse Ankrd26 ${ }^{\text {N-Ank }}$-GFP (B) and mouse Ankrd26 ${ }^{\text {Ank }}$-GFP $(\mathbf{C})$, respectively, in HeLa cells cotransfected with the CherryF to mark the plasma membrane. Insets in B represent 3fold enlargements of boxed areas and highlight the spatial overlap of ms Ankrd26 ${ }^{\mathrm{N}-\mathrm{Ank}}$ with CherryF. Lines in insets mark positions of intensity analyses (see line plots of the red and green fluorescent channel). Bars, $10 \mu \mathrm{m}$. 
Fig EV3 (related to Fig 3). Mouse Ankrd26 binds to membranes via non-electrostatic (i.e. hydrophobic) interactions critically relying on its amphipathic $\mathrm{N}$ terminal structure and recognizes membrane curvatures by its ankyrin repeat array

$(\mathbf{A}, \mathbf{B})$ Attempts of extraction of liposome-bound mouse Ankrd26 ${ }^{\mathrm{N}-A n k}$ using increasing salt concentrations. (A) Representative image of a Coomassie-stained SDS-PAGE gel. (B) Quantitative analyses (B) confirming that also the liposome binding of $\mathrm{ms}$ Ankrd26 ${ }^{\mathrm{N}-\mathrm{Ank}}$ is fully salt-resistant. (C,D) The ankyrin repeat array of mouse Ankrd26 prefers the highly curved membranes of SUVs over the more shallowly curved membrane surfaces of LUVs, as demonstrated by comparative coprecipitations $(\mathbf{C})$ and quantitative analyses thereof $(\mathbf{D})$. Data represent mean \pm SEM. Bar plots with individual data points (dot plots). (B) $n=9$ experiments each; one-way ANOVA with Tukey post hoc test. (D) $\mathrm{n}=6$ experiments each; two tailed, unpaired Student's t-test. $* P<0.05$; $* * P<0.01$; $* * * P<0.001$

Fig EV4 (related to Fig 4). The papillary thyroid carcinoma-associated fusion of Ankrd26 and RET exhibits a membrane localization mediated by the Ankrd26 portion it includes

(A-H) MIPs of indicated proteins in CherryF-cotransfected HeLa cells (A,C,E,G) and subcellular fractionations of lysates of HEK293 cells expressing the indicated proteins (B,D,F,H), as in Fig 4A,C,E,G supplemented with fluorescence intensity plots (arbitrary unites) for the red and the green fluorescence channel along the lines indicated in the insets (see line added), which are magnifications of boxed areas. Bars, $10 \mu \mathrm{m}$. 
A hu Ankrd26-GFP + CherryF Hom. S1 P1 S2 P2 S2' P2' $250-{ }_{\text {anti-GFP }}^{-}-$ $40-$ an- anti-Cherry $\Delta \quad \Delta$

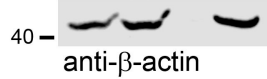

B GFP + CherryF

Hom.S1 P1 S2 P2 S2' P2'

$25-\underset{\text { anti-GFP }}{-}-$

anti-Cherry $-\underset{\mathbf{A}}{-\vec{\Delta}}$

$40-\underset{\text { anti- } \beta \text {-actin }}{-}$

E

Ankyrin repeats

\section{5}

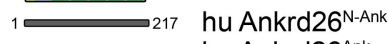

$45 \Longleftarrow 217$ hu Ankrd26 ${ }^{\text {Ank }}$
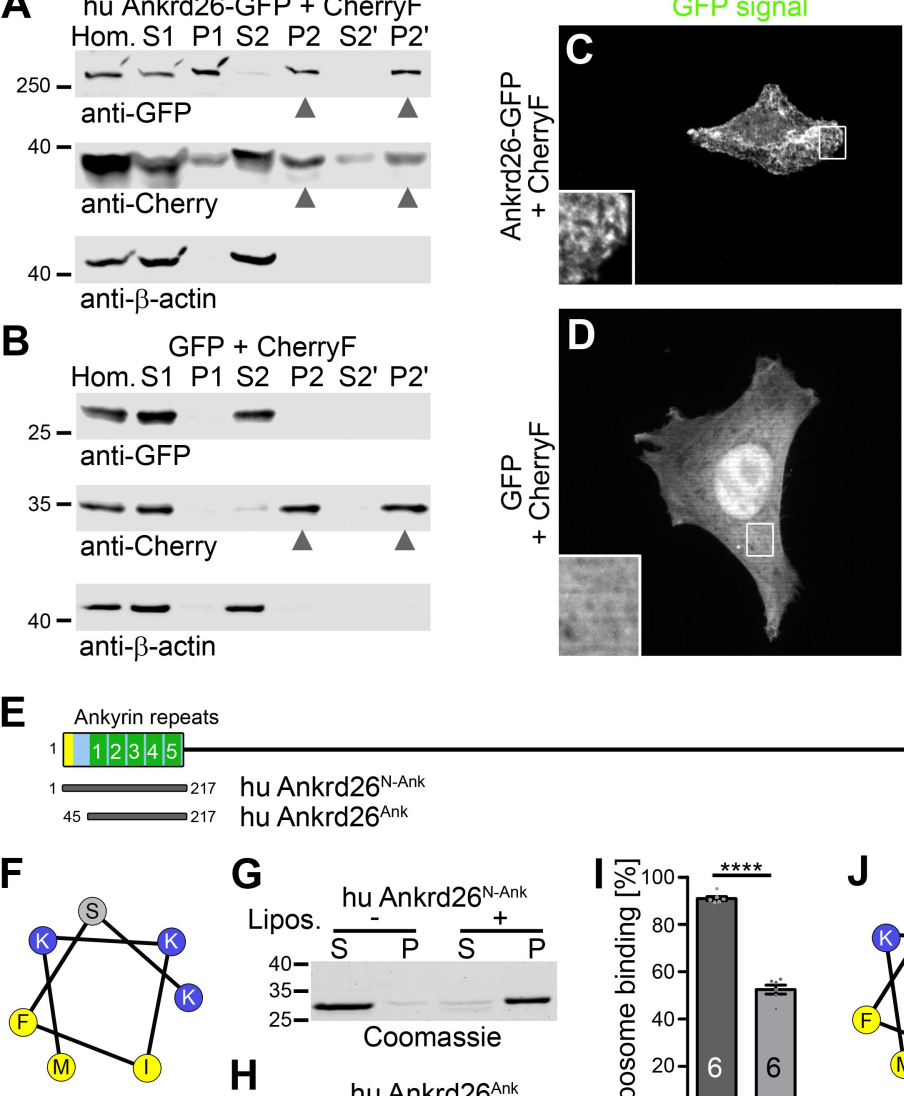

CherryF
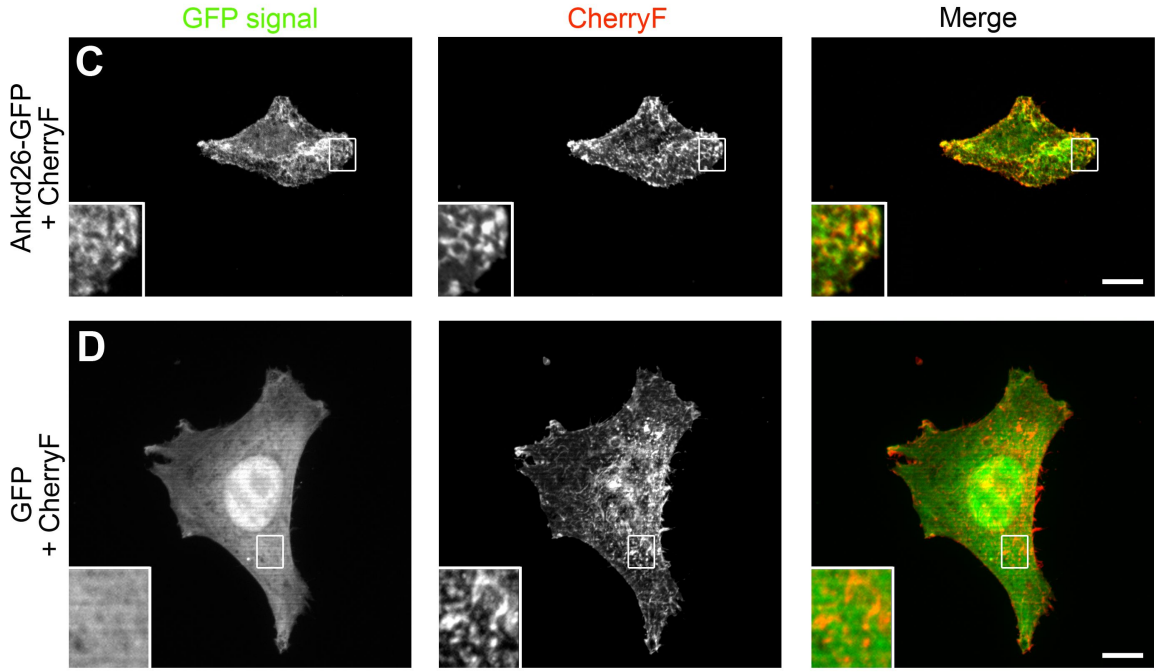

Hu Ankrd26 ${ }^{\text {Ank }}$

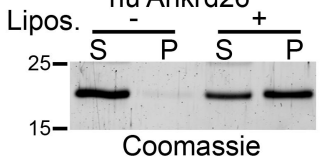

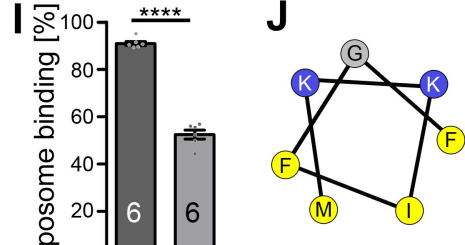

K

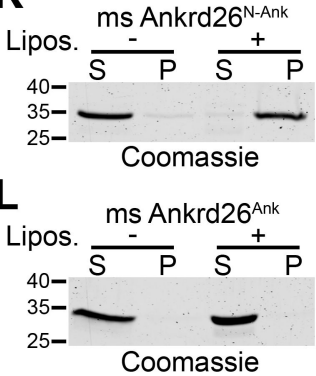

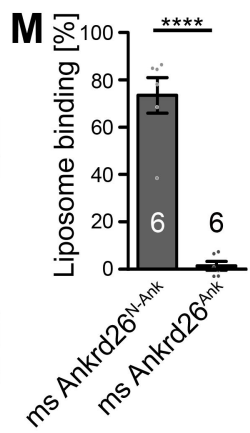

Merge

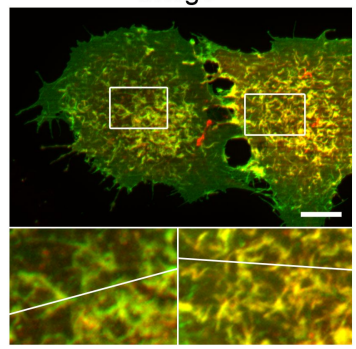

$1 \frac{\text { के }}{\frac{2}{0}}$

Line scan right inset

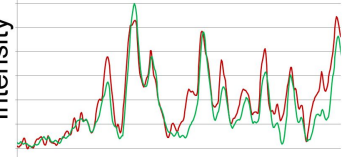

Line scan inset

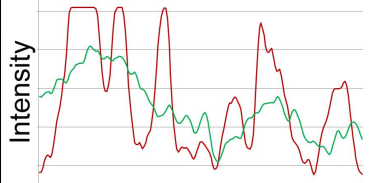



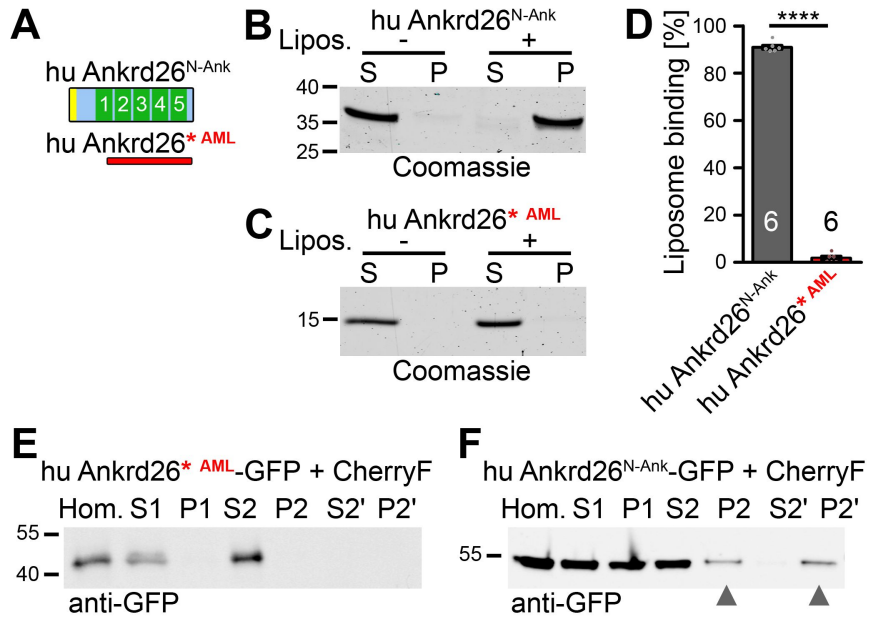

$\boldsymbol{F}_{\text {hu Ankrd26 }}$ N-Ank_GFP + CherryF Hom. S1 P1 S2 P2 S2' P2'

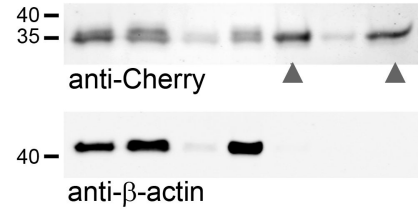

GFP signal

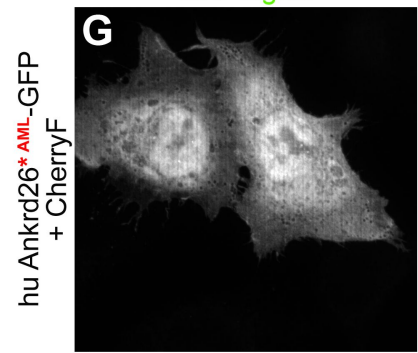

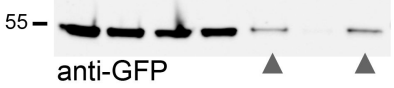
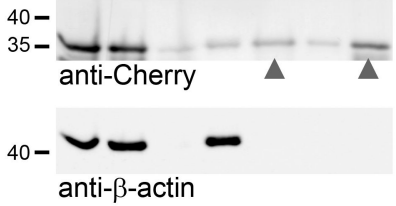

CherryF

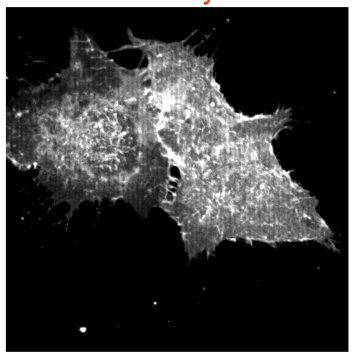

Merge 
hu Ankrd26 $6^{\text {N-Ank }}$

$\mathrm{NaCl} 150 \mathrm{mM} 150 \mathrm{mM} 200 \mathrm{mM} 250 \mathrm{mM}$ Lipos. $\frac{-}{S \quad P} \stackrel{+}{S \quad P} \stackrel{+}{S \quad P} \frac{+}{S \quad P}$

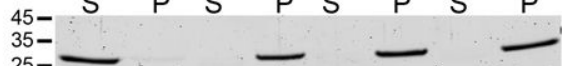

\section{Coomassie}

C

$\mathrm{NaCl} 150 \mathrm{mM} 150 \mathrm{mM} 200 \mathrm{mM} 250 \mathrm{mM}$ Lipos. $\frac{-}{S \text { P }} \stackrel{+}{S \text { P }} \stackrel{+}{S P} \frac{+}{S P P}$

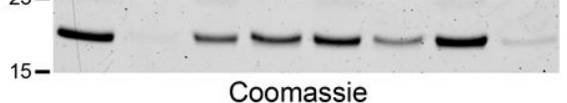

E

rt Ankrd26 MKKIFGFRNKGPSPLGSSARPRSN 24 ms Ankrd26 MKKIFGFRSKGPSPLGPSARPRSN 24

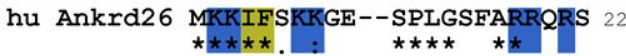

L

hu Ankrd26 N-Ank 14E,F5E

$\mathrm{NaCl} 150 \mathrm{mM} 150 \mathrm{mM} 200 \mathrm{mM} 250 \mathrm{mM}$ Lipos. $\frac{-}{S \quad P} \stackrel{+}{S} \stackrel{+}{S} \frac{+}{S P}$ 35

Coomassie
B ๙ $\left.\sum^{20}\right]$

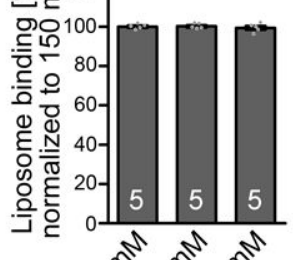
रू

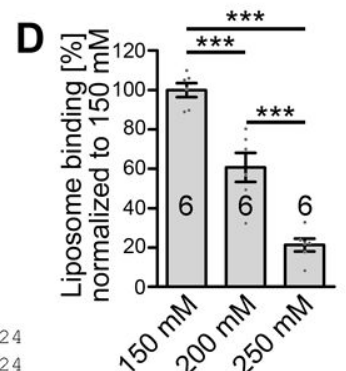

M

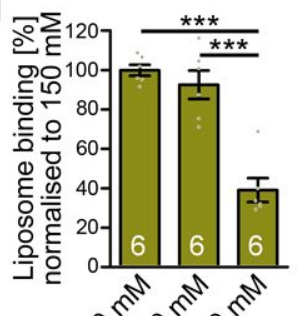
$200^{2} 0,500$

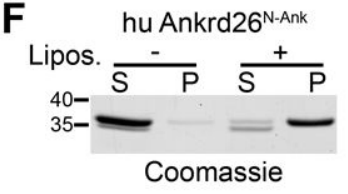

G hu Ankrd26 $6^{\text {N-Ank } 14 E, F 5 E}$
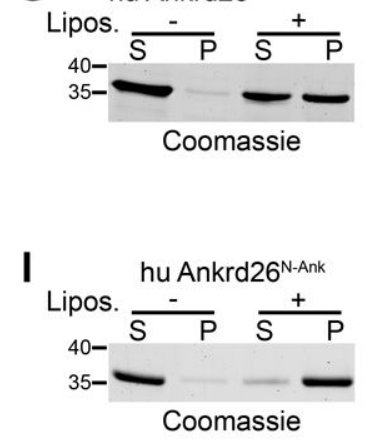

J hu Ankrd26 N-Ank K2A,K3A,K7A,

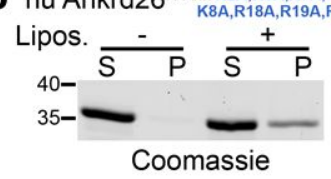

N hu Ankrd26 (Y40-V208)
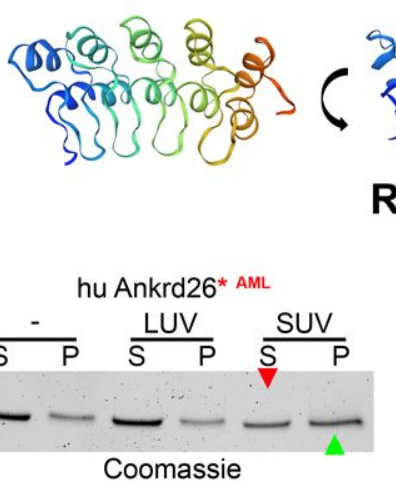

$\mathbf{O}$
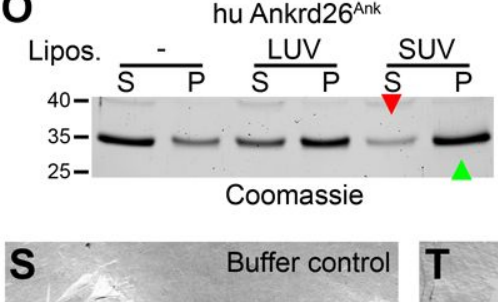

Buffer control
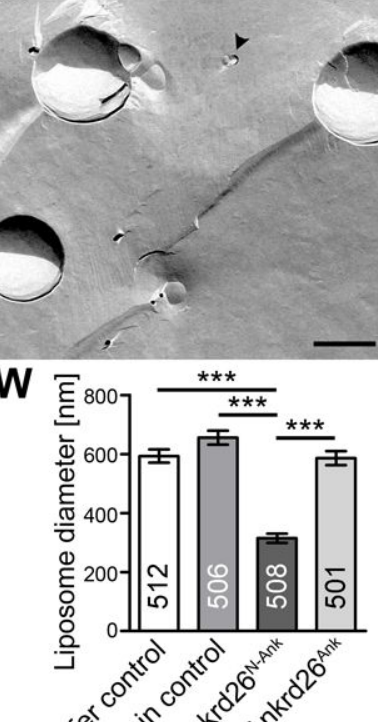

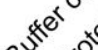

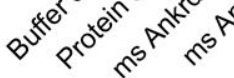
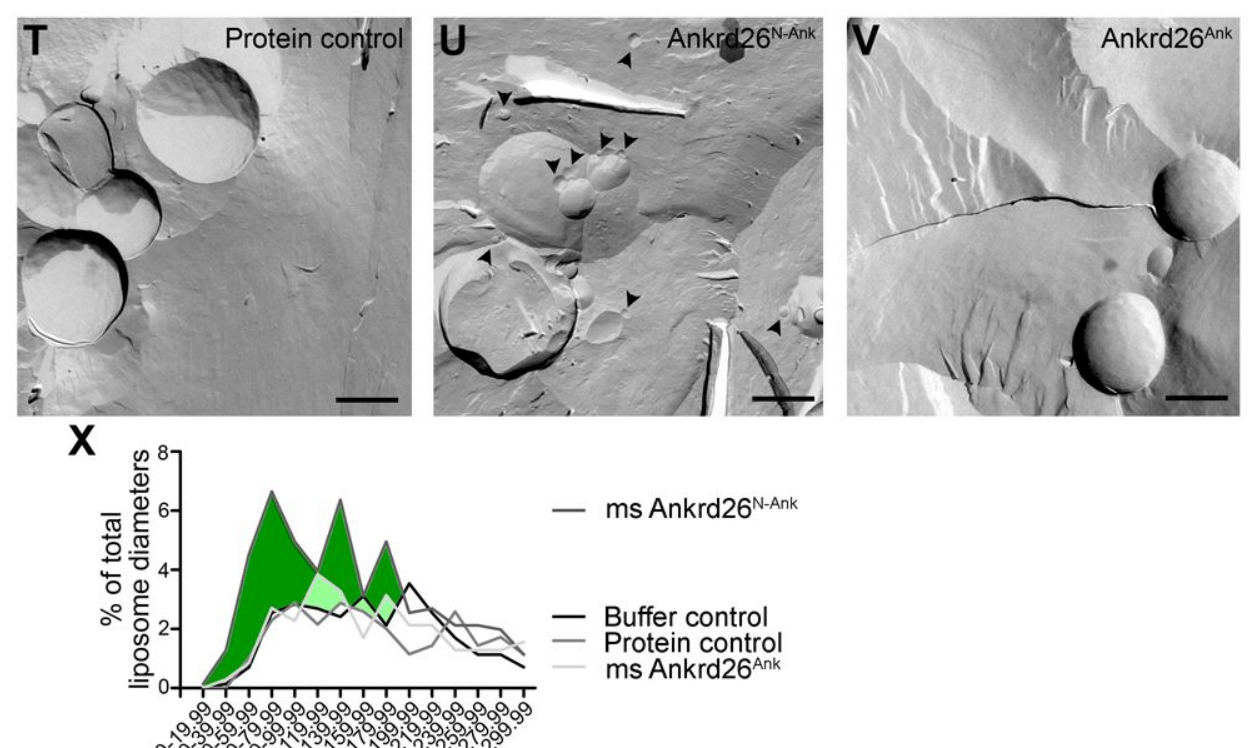

Liposome diameter ranges [nm] 


\section{GFP signal}
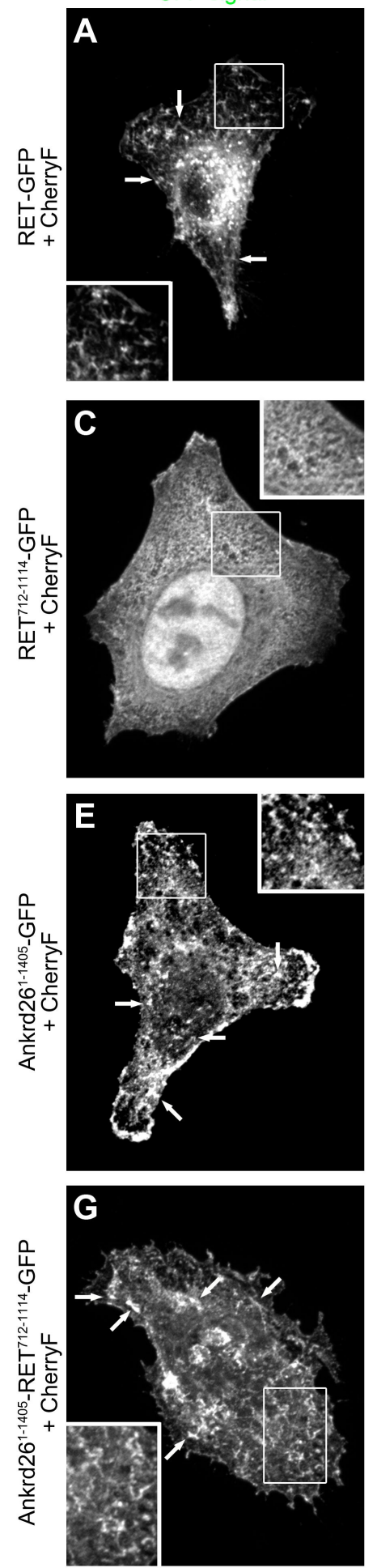

CherryF
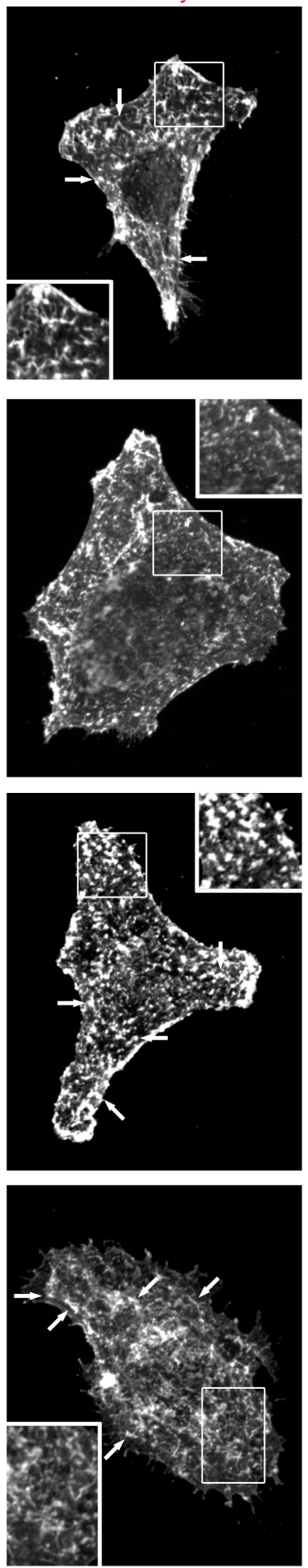

B
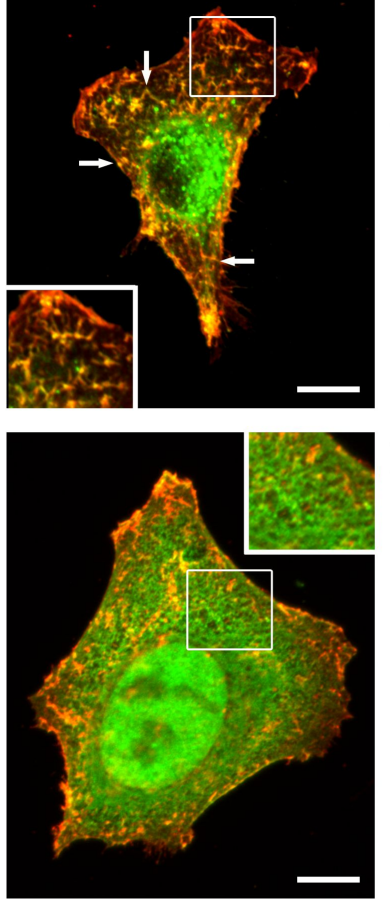

D

\section{RET $712-1114$-GFP} + CherryF

Hom. S1 P1 S2 P2 S2، P2 70- $-\longrightarrow$ anti-GFP

\section{0-}

$35-=----$ anti-Cherry

$40---$

anti- $\beta$-actin

E
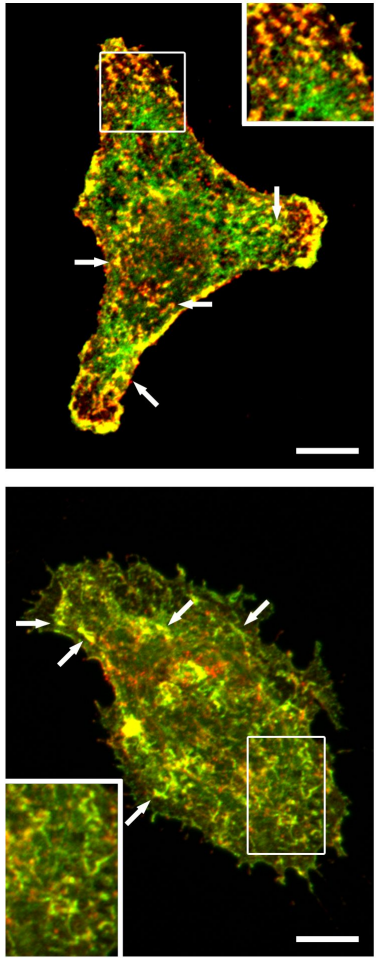

Ankrd26 1-1405-GFP

+ CherryF

Hom.S1 P1 S2 P2 S2‘ P2، 50- $-\infty-\frac{-}{\Delta}$

35anti-Cherry

40- $\sim$

anti- $\beta$-actin

H

Ankrd26 1-1405-RET ${ }^{712-1114}$-GFP + CherryF

Hom. S1 P1 S2 P2 S2'P2، 180- $\div-\frac{-1-}{\text { anti-GFP }}-\cdots$ $\underset{35-}{40-}=-\frac{-}{\Delta}=-\frac{}{\Delta}$

40- - anti- $\beta$-actin 
A
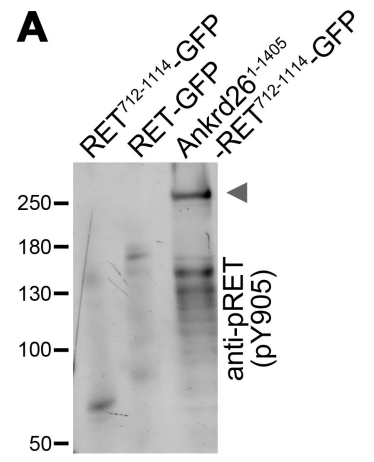

D

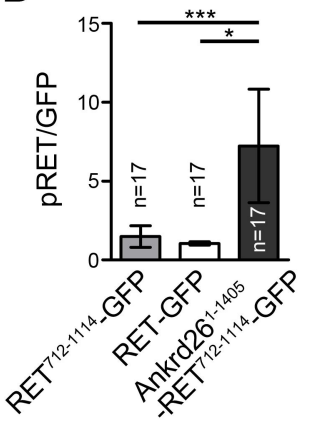

B
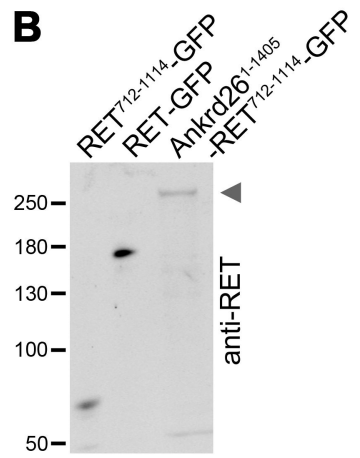

$250-$

$180-$

130-

$100-$

50-

E

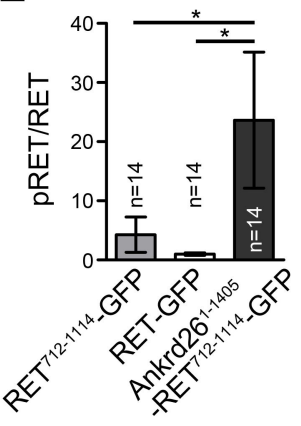

4

亳

京

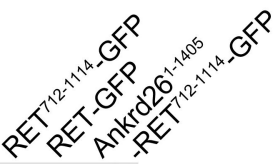

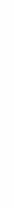

